\title{
La política de orden público en la Restauración
}

\author{
Eduardo GonzÁlez Calleja
}

Prof. Titular. Dpto. H. ${ }^{a}$ Contempránea. Universidad Carlos III de Madrid The public order policy in Restoration Spain

\begin{abstract}
RESUMEN
Durante la etapa de la Restauración (1875-1931), en España se configuró un sistema estatal de seguridad pública militarizado, centralizado y burocrático en organización, función y doctrina. La diferente estructura de seguridad en los ámbitos rural y urbano, la escasez de recursos materiales y la errática voluntad política de un poder civil lastrado por su debilidad ante el pretorianismo dificultaron la implantación de un modelo nacional unificado de orden público. Prevaleció el empleo abusivo del estado de excepción, y la primacía del Ejército sobre una Policía que abordó su modernización en épocas más tardías que sus homólogas europeas.

La agudización de la protesta política a partir de 1917 condujo a un desmoronamiento progresivo del sistema de orden público que la militarización extrema emprendida durante la Dictadura de Primo de Rivera no pudo contener con eficacia.

PALABRAS CLAVE Ejército, España, Orden Público, Policía, Restauración, Violencia Política
\end{abstract}

\begin{abstract}
During the times of the Restoration Spain (1875-1931) was built a state system of public security militarized, centralized and bureaucratic in organization, function and doctrine. The different structure of security in the rural and urban spaces, the shortage of material resources and the erratic political will of a civil power weakened face to the praetorianism made difficult the implantation of a unified national model of public order. It prevailed an abusive use of the state of emergency, and the primacy of the Army over a Police system that reached the first stages modernization later than its European homologous. The rise of the political protest since 1917 leaded a progressive decline of the system of public order that the extreme militarization during the Primo de Rivera's Dictatorship could not effectively contain.
\end{abstract}

\section{KEY WORDS}

Army, Restoration, Policy, Political

Violence, Public Order, Spain 
Con la Restauración comenzaron a cristalizar una serie de procesos estrechamente ligados al desarrollo del capitalismo en España. Uno de ellos fue la estructuración de la sociedad entera a partir del funcionamiento de una serie compleja de dispositivos de vigilancia, moralización e individualización, que tenían como fin el mantenimiento del orden social establecido. El «orden social», entendido como plasmación inamovible, naturalizada e idealizada de los valores y los intereses de los grupos dominantes, tuvo uno de sus reflejos prácticos en un peculiar modo gestionar de los asuntos del orden público, que impregnaría la ejecutoria del régimen hasta su desaparición ${ }^{1}$. No se trataba de salvaguardar los derechos cívicos según la moderna doctrina de la seguridad ciudadana, sino de fiscalizar su ejercicio, y, en caso necesario, limitarlos o suspenderlos cuando, en opinión de las instancias estatales encargadas de estos menesteres, se alcanzaban o se rebasaban los límites de la subversión institucional. La defensa coactiva del «orden social» fue una alternativa siempre presente, y la fuerza fue la opción preferida por los poderes públicos en las coyunturas de crisis social y política, de modo que el resto de las posibles alternativas de control colectivo (disuasión, demostración, cooptación, reformismo, etc.) aparecieron como marginales o supeditadas al éxito de la misma.

En el sentido estricto de su eficacia funcional, el Estado español ha acreditado históricamente su brutalidad, ya que las fuerzas del orden, y sobre todo el Ejército, han mostrado falta de voluntad y de capacidad para aplicar una represión proporcional a la violencia desplegada en su contra ${ }^{2}$. La prioridad dada a sus capacidades coercitiva (orden público) y extractiva (fiscalidad) sobre las facetas de negociación (régimen político representativo, garantía jurídica de los derechos políticos y sociales) y distribución de recursos (educación, asistencia social y laboral, abastecimiento, etc. ${ }^{3}$ ) puede haberse debido a la configuración predominantemente militar de la organización burocrática del Estado nacional, que es un hecho patente desde los albores del liberalismo, pero que puede rastrearse en épocas anteriores ${ }^{4}$.

1 Sobre el concepto de «orden social» en la época, véanse Juan ANTÓN MELLÓN, «La defensa social: liberalismo y contrarrevolución en la España de fines del siglo XIX», Estudios de Historia Social, n. ${ }^{\circ}$ 54-55, enero-diciembre, pp. 237-306; Antonio ELORZA, «La ideología liberal ante la Restauración: la conservación del orden», en La utopía anarquista bajo la Segunda República Española, precedido de otros ensayos, Madrid, Ayuso, 1973, pp. 123-154; Carlos GIL ANDRÉS, Protesta popular y orden social en La Rioja de fin de siglo, 1890-1905, Logroño, IER, 1995, pp. 161-172; Eduardo GONZÁLEZ CALLEJA, «La defensa armada del 'orden social' durante la Dictadura de Primo de Rivera (1923-1930)», en José Luis GARCÍA DELGADO (ed.), España entre dos siglos (1875-1931). Continuidad y cambio, Madrid, Siglo XXI, 1991, pp. 61-77; Antoni JUTGLAR, Actitudes conservadoras ante la realidad obrera en la etapa de la Restauración, Algorta, Zero, 1970 (también en Revista de Trabajo, n. ${ }^{\circ} 25,1969$, pp. 47-71) y María Victoria LÓPEZ-CORDÓN, «La mentalidad conservadora durante la Restauración», en José Luis GARCÍA DELGADO (ed.), La España de la Restauración. Política, economía, legislación y cultura, Madrid, Siglo XXI, 1985, pp. 71-109.

2 Demetrio CASTRO ALFÍN, «Agitación y orden en la Restauración. ¿Fin del ciclo revolucionario?», Historia Social, n. ${ }^{\circ}$ 5, otoño 1989, p. 46.

3 Charles TILLY, Coerción, capital y los estados europeos, 990-1990, Madrid, Alianza, 1992, pp. 9192 y $149-153$.

4 Véanse Manuel BALLBÉ, Orden público y militarismo en la España constitucional (1812-1983), 2. ${ }^{a}$ ed., Madrid, Alianza, 1985, p. 20 y Rafael CRUZ, «La Lógica de la Guerra. Ejército, Estado y Revolu- 
Según Ballbé, la crisis de la Restauración estuvo originada en parte por la defectuosa estructuración de las instituciones militarizadas de orden público, ya desde los prolegómenos del régimen ${ }^{5}$. El liberalismo dominante en el último cuarto del XIX recibió como legado de su conflictivo proceso de consolidación estatal un sistema de seguridad fuertemente regresivo, centralizado y burocrático en organización, función y doctrina. Un modelo de orden público dictado por razones políticas antes que profesionales, lo que explica la preferencia por el control estratégico de la capital y por la ocupación militar del territorio, la mayor preocupación por el delito político que por la delincuencia común, y la concepción de la seguridad como imposición y coacción estatal, antes que como derecho ciudadano ${ }^{6}$. La diferente estructura de seguridad en los ámbitos rural (policías regionales y Ejército en dependencia de las Capitanías Generales y las Audiencias) y urbano (atribuciones compartidas por las autoridades judiciales, locales y gubernativas), junto a otros factores (la penuria presupuestaria, la doble dependencia orgánica de las autoridades civil y militar, la escasa voluntad y continuidad políticas, motivada en parte por la inestabilidad político-administrativa propia del tránsito al régimen liberal), dificultaron la implantación de un modelo nacional unificado de orden público. Ello condujo, a partir de 1844, a la adopción de una estructura mixta, predominantemente militar en el campo (Guardia Civil) y civil en el espacio urbano (Policía de de Protección y Seguridad, militarizada en 1870 como Cuerpo de Orden Público), con un despliegue provincial que evolucionó muy lentamente hacia un modelo civil nacional y centralizado a lo largo de la Restauración ${ }^{7}$.

\section{EL PECADO ORIGINAL: LA MILITARIZACIÓN DEL ORDEN PÚBLICO}

Al igual que en el resto del mundo, uno de los principales elementos de vertebración histórica de la presencia estatal en España ha sido el Ejército. De hecho, los esfuerzos de centralización administrativa iniciados en el siglo XVIII se inspiraron en modelos de eficiencia militar que, en la práctica, se tradujeron en la presencia del Ejército en tareas administrativas estrictamente civiles, trasladando a la jurisdicción militar responsabilidades políticas fundamentales, como la salvaguardia del orden público. A la larga sombra que los capitanes generales (la todopoderosa figura institucional a la que el ordenamiento jurídico absolutista dieciochesco adjudicó el «gobierno económico-político de las provincias») proyectaron sobre la administración interior se añadía la indefinición constitucional de las funciones que el Ejército (en permanente pugna de competencias con la Milicia Na-

ción en la España contemporánea», Studia Historica-Historia Contemporánea, vol. X-XI, 1992-93, pp. 212-215.

${ }^{5}$ BALLBÉ, Orden público y militarismo en la España constitucional, p. 305.

${ }^{6}$ Diego LÓPEZ GARRIDO, El aparato policial en España. Historia, sociología e ideología, Barcelona, Ariel, 1987, pp. 64-67.

7 Martín TURRADO VIDAL, Estudios sobre historia de la Policía, Madrid, Secretaría General Técnica del Ministerio del Interior, 1986, vol. I, pp. 50 y 70. 
cional y con las autoridades civiles) debía desempeñar en la defensa integral del Estado ${ }^{8}$.

Algunos sociohistoriadores, como Anthony Giddens, Charles Tilly o Michael Mann, han destacado que la diferenciación entre Policía y Ejército permanente o Fuerzas Armadas se ha mantenido con suficiente claridad en la mayoría de los países europeos desde mediados del siglo XIX, cuando los Estados fueron diseñando un modelo tripartito de división del trabajo represivo en Policía, fuerzas paramilitares de seguridad y Ejército regular, para afrontar con eficacia los distintos niveles de amenaza contra el orden social, desde las intentonas revolucionarias hasta los delitos comunes. De este modo, el Estado-nación surgido del proceso revolucionario burgués forjó un «nuevo aparato disciplinar del poder» basado en el control y en el virtual monopolio de la fuerza, aplicados en dosis suficientes para casi desarmar a la población. La autoridad coercitiva se reforzaba después de cada conmoción revolucionaria. Además, el aumento en importancia de la Policía aparecía disociada funcionalmente, pero a la vez relacionada estratégicamente, con el modelo de «supervisión» disciplinaria de las relaciones laborales de tipo capitalista ${ }^{9}$.

En la mayor parte de los países europeos, la función militar se fue integrando gradualmente en la nueva estructura de orden público, más flexible y adecuada al control óptimo de los niveles intermedios del disentimiento colectivo. Pero en países como España, la escasa especialización, la ineficacia y la indocilidad de estos instrumentos de represión resultaban un indicio plausible para calibrar las limitaciones del Estado nacional en sí mismo, y en relación con el escaso desarrollo de una infraestructura capitalista industrial que pudiera justificarlo y reforzarlo ${ }^{10}$. La débil y desigual implantación de la ciudadanía social y política permitió al Ejército conservar por más tiempo su papel dominante en el control de la protesta interna (sobre todo contra las fuerzas regionales o de clase que reivindicaban la ampliación de los derechos de ciudadanía), y emplear los cuatro niveles tradicionales de actuación coactiva (la conciliación, el servicio policial convencional, el empleo demostrativo de la fuerza y la escalada de la violencia real), para lo que dispuso de un repertorio de acción más amplio y de una parafernalia más apta que en épocas anteriores ${ }^{11}$.

8 Véanse Martín TURRADO VIDAL, Estudios sobre historia de la Policía, Madrid, Secretaría General Técnica del Ministerio del Interior, 1991, vol. II, pp. 13-16 y Roberto L. BLANCO VALDÉS, Rey, Cortes y fuerza armada en los orígenes de la España liberal (1808-1823), Madrid, Siglo XXI, 1988.

9 Sobre la importancia de la Policía en la edificación del Estado moderno, véanse Charles TILLY, Allan LEVETT, A.Q. LODHI y Frank MUNGER, «How Policing Affected the Visibility of Crime in Nineteenth-Century Europe and America», Working Paper 115, Centre for Research on Social Organization, University of Michigan, 1975 y Anthony GIDDENS, «Estado y violencia», Debats, n. ${ }^{\circ}$, pp. 81-90 y The Nation-State and Violence, vol. II de A Contemporary Critique of Historical Materialism, Cambridge, Polity Press, 1985. Una exposición más amplia de tales hipótesis, en Anthony GIDDENS, «Espacio, tiempo y política en la teoría social», Debats, n. ${ }^{\circ} 14$, diciembre 1985, pp. 90-101 y Charles TILLY, La France conteste de 1600 à nos jours, París, Fayard, 1986, pp. 400-401 y Coerción, capital y los Estados europeos, p. 94.

10 Sobre esta cuestión, véase Rafael CRUZ, «Crisis del Estado y acción colectiva en el período de entreguerras, 1917-1939», Historia Social, n. ${ }^{\circ}$ 15, invierno 1993, pp. 119-136.

11 Michael MANN, Las fuentes del poder social, II. El desarrollo de las clases y los Estados nacionales, 1760-1914, Madrid, Alianza, 1997, pp. 530-539. 
Rafael Cruz ha destacado que la intervención del Ejército en el control de la acción colectiva de protesta ha supuesto el mantenimiento de la autonomía de los militares respecto de los gobernantes civiles y su predominio como actor político independiente $^{12}$. A lo largo del siglo XIX, el Ejército fue asumiendo un papel cada vez más decisivo en las tareas del Estado: su especialización y casi monopolio de la seguridad interior acentuó su independencia con respecto a los poderes públicos, hasta constituir un poder alternativo al político, en función de su presunta capacidad para imponer un orden social efectivo y preservar la unidad nacional ${ }^{13}$. Las fuerzas armadas han intervenido frecuentemente de forma autónoma en los conflictos que enfrentaban al capital con el trabajo, al centro con la periferia o al gobierno con la oposición, provocando una mayor intensidad y frecuencia de la violencia. Las peculiaridades del control militar de la acción colectiva no facilitaron el desarrollo de una acción no violenta, ni el tránsito hacia actitudes reformistas. Como señala Tilly, la preponderancia militar minimizó las posibilidades de negociación que, en otras partes de Europa, posibilitaron la formulación de derechos individuales y sociales para los ciudadanos y restricciones para las prerrogativas del Estado ${ }^{14}$.

El entramado legal restauracionista encargó la defensa física del orden público a instrumentos gubernamentales específicos, cuya misión coercitiva y represiva quedó perfectamente definida, enmarcada y reconocida en el nuevo ordenamiento constitucional. El Gobierno contaba en primer y casi único lugar con el Ejército, considerado por Cánovas como «un instrumento del Estado; el primero, el más alto y el más noble, a mi juicio, para mantener la independencia nacional y la integridad del territorio, para defender el orden público y los intereses sociales». Por ello, las Fuerzas Armadas, fortalecidas en su papel semipolicial por la Ley Constitutiva del Ejército de 29 de noviembre de 1877, la Ley Orgánica de 1878 y la Ley Adicional de 19 de julio de 1889, debían ser «por largo plazo, quizá por siempre, robusto sostén del presente orden social e inevitable dique a las tentativas ilegales del proletariado, que no logrará por la violencia otra cosa sino derramar inútilmente su sangre en desiguales batallas ${ }^{15}$.

La asunción por parte del Ejército de las funciones de salvaguardia del orden interior no era una cuestión baladí. Por ese entonces, las fuerzas armadas regulares, incluyendo entre las mismas a la Guardia Civil, eran la única baza fiable para

12 Rafael CRUZ, «La Lógica de la Guerra. Ejército, Estado y Revolución en la España Contemporánea», Studia Storica-Historia Contemporánea, vol. X-XI, 1992-93, pp. 207-222.

13 Manel RISQUES, Soledad BENGOECHEA, Susanna TAVERA y Josep M. ROIG I ROSICH, «Unes relacions determinades per la violencia», en Borja de RIQUER (ed.), Història. Política, Societat $i$ Cultura dels Països Catalans, vol. 8: L'Época dels nous moviments socials, 1900-1930, Barcelona, Enciclopèdia Catalana 1995, p. 202.

14 TILLY, Coerción, capital y los estados europeos, pp. 124-125.

15 La primera cita de Cánovas, en Diario de Sesiones de las Cortes, Congreso de los Diputados, 7III-1888, p. 1661. La segunda, en «La cuestión obrera y su nuevo carácter» (discurso en el Ateneo de Madrid, 10-XI-1890), en Antonio CÁNOVAS DEL CASTILLO, Discursos en el Ateneo (Obras Completas, vol. I), Madrid, Fundación Cánovas del Castillo, 1981, p. 226. 
la construcción de un sistema estatal de orden público, además de ser uno de los pocos instrumentos vertebradores del nacionalismo español tal como había sido concebido e interpretado por las diversas corrientes liberales a lo largo del siglo XIX. De suerte que, reconociendo implícitamente la ineficacia de las estructuras gubernativas del poder civil, un Real Decreto de 22 de marzo de 1893 ratificó la división del país en circunscripciones político-militares: siete Regiones dirigidas por capitanes generales o tenientes generales, además de cinco Comandancias Generales en Baleares, Canarias, Campo de Gibraltar, Ceuta y Melilla. Cada provincia estaría controlada además por gobernadores militares, omnipotentes cuando la autoridad civil recurría al Ejército para hacer frente a las frecuentes alteraciones sociales. El nuevo ordenamiento legal otorgó una amplia libertad a los militares para organizarse de forma autónoma: de 1874 a 1923, 34 generales accedieron al cargo de ministro de la Guerra, por sólo cuatro civiles. Desde el gobierno se emitieron unas completas directrices sobre orden público, donde las Fuerzas Armadas siempre tuvieron un papel estelar acorde con su «vocación interior»: el de garante último del sistema político a través de dos importantes resortes de poder. En primer lugar, la capacidad para constituir y dirigir jurisdicciones especiales de marcado carácter represivo, según lo establecido en la Ley de Enjuiciamiento Militar de 29 de septiembre de 1886 (que mantenía la jurisdicción de guerra en los insultos a la Guardia Civil o «a cualquier instituto que preste servicio análogo»), el Código de Justicia Militar de 27 de septiembre de 1890 (que confería similares atribuciones a los tribunales castrenses en los casos de incitación a la rebelión militar o sedición por parte de civiles, y solucionaba las injurias u ofensas de palabra o por escrito a las autoridades e instituciones militares), la Ley de $1 .^{\circ} \mathrm{de}$ enero de 1901 (que sustrajo del juicio por Jurado los delitos contra las autoridades civiles, militares o eclesiásticas) y la polémica Ley de Jurisdicciones de 23 de marzo de 1906, por la que las injurias a las Fuerzas Armadas o los ataques contra la unidad nacional fueron juzgadas a partir de entonces por la autoridad militar.

La omnipresencia del Ejército en las tareas de salvaguardia del orden público no impidió, sino que estimuló el fortalecimiento de la acción del Estado a escala nacional. Desde fines del siglo XIX se produjo una paulatina pérdida de influencia de la intermediación de los poderosos locales en las relaciones entre la administración central y el conjunto del país, lo que permitió desde la segunda década del siglo XX una mayor implantación del Estado en una sociedad territorializada de forma nacional, a través de la regulación exhaustiva de las actividades sociales con la utilización de la ley y de la organización militar ${ }^{16}$. Pero esta mayor presencia no implicó una mayor eficacia a la hora de conciliar intereses dentro y fuera del entramado estatal. La dependencia predominantemente castrense y la adecuación de los recursos coactivos a los requerimientos del Estado centralizador en la España rural hicieron que los sucesivos gobiernos no se atrevieran o no consideraran necesario impulsar la creación de un cuerpo civil de salvaguardia, de modo que la Policía sur-

16 CRUZ, «Crisis del Estado y acción colectiva en el período de entreguerras», p. 125. 
gió, diversificó sus funciones y se extendió por el territorio mucho más tarde que en otros países europeos.

La Restauración también se apoyó en una Administración de Justicia reafirmada en su papel represivo por la promulgación de normas impregnadas de valores conservadores, por la concepción de una técnica jurídica al servicio del control social (legitimada además por la aparición y desarrollo de un saber de marcada impronta positivista como es la criminología), y por las diversas normativas de excepción que se fueron elaborando a medida que las manifestaciones de disidencia se hicieron más graves. Como en la mayoría de los países europeos desde las «tormentas del 48», y sobre todo desde la década de 1870, los derechos y libertades establecidos en las Constituciones liberales pasaron a ser férreamente administrados y minuciosamente regulados por los poderes públicos. Además de los códigos constitucionales, otras leyes pueden influir en el control de la protesta. La legislación sobre orden público y manifestaciones, los derechos de la Policía y de los ciudadanos, o - como ya hemos visto- la organización de los aparatos represivos (militarización, centralización, especialización...) influyen en el abanico de opciones que un régimen puede emplear para afrontar la contestación política y social ${ }^{17}$.

El régimen de la Restauración no introdujo un modelo propio de Policía Gubernativa, sino que mantuvo el organigrama provincial existente antes del Sexenio y que había sido parcialmente reformado el 2 de julio de 1870, cuando se creó un Cuerpo de Orden Público con personal y organización civiles. La estructura civil de salvaguardia del orden, heredada del Sexenio, que sometida a reformas continuadas, insuficientes y a menudo contradictorias, como el Reglamento de Policía de 11 de noviembre de 1878, modificado el 18 de octubre de 1887, y el Real Decreto de 26 de octubre de 1886 que establecía la Dirección General de Seguridad y Orden Publico, suprimida a su vez el 10 de octubre de 1888. Los ensayos de reforma no alteraron la mala situación interna de la Policía, al no eliminar la tutela militar de la institución, centrarse sólo en los problemas organizativos y jurisdiccionales y no actuar sobre el meollo del «problema policial», que era fundamentalmente económico, político y de capacitación técnica. Con cada cambio de gabinete, la casi totalidad de delegados, inspectores y agentes de Policía pasaban a la condición de cesantes. Los estímulos profesionales eran casi inexistentes, y los agentes soportaban una escasez crónica de medios materiales. La Policía mostró su ineficacia para afrontar la labor antiterrorista de la década de los noventa, que precisó de la promulgación de una legislación y de una organización policial especiales. Otra cuestión pendiente era la coordinación entre las diversas instituciones de salvaguardia del orden, asunto que tenía estrecha relación con la nunca resuelta controversia sobre la preeminencia del poder civil o el castrense en circunstancias de especial gravedad para la tranquilidad pública. Desde comienzos

17 Donatella DELLA PORTA, Social Movements, Political Violence, and the State. A Comparative Analysis of Italy and Germany, Cambridge, Cambridge University Press, 1995, p. 72. 
del siglo XX se observó una progresiva militarización del Cuerpo de Seguridad, cuyos jefes y oficiales procedían casi en exclusiva de la Guardia Civil y del Ejército, con todo lo que ello comportaba de percepción unilateral de las cuestiones policiales desde un sesgo predominantemente castrense ${ }^{18}$. La Guardia Civil, con una instrucción profesional típicamente militar, ha desarrollado y desarrolla su labor bajo el Código de Justicia Militar, pero en contacto continuo con las autoridades militares y civiles, dependiendo para sus servicios de Ministerio de la Gobernación. El pulso entre autoridades civiles y militares se extendió incluso a los cuerpos especiales de investigación que tuvieron una actuación más que dudosa en la lucha antianarquista de fines del siglo XIX.

\section{LOS CONDICIONAMIENTOS LEGALES: LA APLICACIÓN ABUSIVA DE LAS MEDIDAS DE EXCEPCIÓN}

El régimen de la Restauración no introdujo un modelo propio de seguridad, sino que mantuvo en esencia la estructura legal establecida durante el Sexenio. Hasta 1933 se mantuvo vigente la Ley de Orden Público de 23 de abril de 1870, emitida durante la regencia de Serrano bajo inspiración de la Ley homónima de González Bravo de 1867, que regulaba las medidas que podían adoptar la autoridades civiles y militares en defensa del orden público y la Constitución, y que establecía dos estados excepcionales: el estado de prevención, que debía ser declarado por el Gobierno mediante una ley que debía ser refrendada a posteriori por las Cortes, y el estado de guerra, que podrá ser declarado sin intervención de las Cortes, puesto que esta situación excepcional no se consideraba suspensión de garantías ${ }^{19}$.

En teoría, el texto de la Constitución de 1876 no difería esencialmente de la norma básica de 1869 y de las de otros países liberales en lo referente a la garantía de los derechos fundamentales regulados por la Ley de Orden Público. Sin embargo, el texto del artículo 17 conculcaba uno de los principios de salvaguardia pública establecidos desde la Constitución de Cádiz, al estipular que sólo podrían suspenderse las libertades públicas de forma temporal y por medio de una ley ad hoc, pero otorgando al Gobierno la potestad de suspender las garantías individuales en caso de no estar reunidas las Cortes, a las cuales se solicitaría a posteriori una ratificación de la medida. Lo que en realidad se sancionaba era la discrecionalidad del Ejecutivo para usar y abusar de los estados excepcionales, suspendiendo las garantías con el Parlamento cerrado, y solicitando después de éste un «bill de indemnidad» que legitimase su proceder. Rara vez se respetaron las formas constitucionales que estipulaban la suspensión de garantías con arreglo a una Ley específica. Por el contrario, la norma legal se hizo excepción: hasta 1931

\footnotetext{
18 Antonio MORALES VILLANUEVA, Las fuerzas de orden público, Madrid, San Martín, 1980, p. 146.

19 Pedro CRUZ VILLALÓN, Estados excepcionales y suspensión de garantías, Madrid, Tecnos, 1984, p. 41 y El estado de sitio y la Constitución. La constitucionalización de la protección extraordinaria del Estado (1789-1878), Madrid, Centro de Estudios Constitucionales, 1980, pp. 418-424.
} 
se suspendieron garantías por Real Decreto 32 veces, y sólo dos lo fueron por Ley discutida en las Cortes. A veces, la suspensión de garantías no se motivaba en causas graves de orden público, sino que obedecía a dudosos intereses políticos. Algunos gobiernos llegaron incluso a la aberración de suspender las sesiones parlamentarias para publicar horas después con toda tranquilidad el Real Decreto de suspensión de garantías. De todos modos, frente a un Parlamento excesivamente puntilloso, siempre quedaba el recurso a la declaración, fulminante e inapelable, del estado de guerra, que no requería la fiscalización de las Cortes.

Con el empleo de tales procedimientos, las autoridades civiles y militares pudieron suspender en más de un centenar de ocasiones las garantías constitucionales mediante el recurso a la Ley de suspensión, al Real Decreto ministerial o al más expeditivo del bando de declaración del estado de guerra, lo que representa más de dos medidas suspensivas por año ${ }^{20}$. Durante la Restauración, el conjunto de los ciudadanos tuvo sus derechos básicos en entredicho durante un total de 14,2 años, y la suspensión parcial de garantías a escala local, provincial o regional afectó a importantes masas de población por 11,4 años más. En suma, un 25 de los 56 años de duración del régimen monárquico (un 38,6 por 100 si omitimos la Dictadura de Primo de Rivera) transcurrió con las libertades públicas gravemente limitadas en todo o parte del territorio nacional, lo cual arroja un porcentaje del $45,6 \%$ del tiempo bajo estado de excepción y más de dos medidas suspensivas por año ${ }^{21}$ (véase cuadro 1). A pesar de las opiniones de algunos historiadores, que tienen una percepción selectiva del régimen alfonsino e identifican acríticamente a la Monarquía restaurada con el liberalismo, y a éste con el garantismo absoluto ${ }^{22}$, la suspensión de los derechos constitucionales fue un recurso extremo de defensa empleado de forma claramente abusiva por casi todos los gobiernos - aunque con más énfasis por los conservadores-, y que en determinadas regiones de España caracterizadas por una conflictividad sociopolítica aguda, como fue el caso de Cataluña, acabó siendo el régimen habitual de vida durante períodos muy dilatados. En efecto, entre 1875 y 1931, 7.538 días (36,6\% del total) transcurrieron en el Principado (que contaba con cerca de dos millones de habitantes a inicios del siglo XX, lo que representaba el 10,6\% de la población total de España) con los dere-

20 Una relación pormenorizada de los decretos y leyes de suspensión de garantías y declaración del estado de guerra, en Eduardo GONZÁLEZ CALLEJA, La razón de la fuerza. Orden público, subversión y violencia política en la España de la Restauración, Madrid, CSIC, 1998, pp. 65-73.

21 GONZÁLEZ CALLEJA, La razón de la fuerza, pp. 56-61. El período más largo sin garantías individuales correspondió a la Dictadura de Primo de Rivera, pero hubo también otras etapas de fuerte restricción de las libertades públicas, como la «dictadura Cánovas» de 1876-1878, la coyuntura de cambio de siglo (1895-1902) y el período de la posguerra mundial (1919-1921).

${ }_{22}$ Véase, por ejemplo, Mercedes CABRERA y Fernando del REY REGUILLO, El poder de los empresarios. Política y economía en la España contemporánea (1875-2000), Madrid, Taurus, 2002, pp. 147149 , donde se minusvalora el componente represivo de tales medidas, disculpadas en aras de una abstracta lógica de la brutalización de la vida política donde se opta por separar de forma artificial las actuaciones del poder civil y el militar. Sobre el error de definir acríticamente la Restauración como un régimen plenamente liberal desde sus inicios hicimos algunas consideraciones generales en Eduardo GONZÁLEZ CALLEJA, El máuser y el sufragio. Orden público, subversión y violencia política en la crisis de la Restauración (1917-1931), Madrid, CSIC, 1999, pp. 11-17. 
chos cívicos en suspenso, 2.127 de los cuales (10,3\%) correspondieron en solitario a la ciudad de Barcelona, la más poblada de España con 544.000 habitantes en 1900 (véase cuadro 2). La suspensión de garantías, que en muchas ocasiones fue la coartada utilizada para desplegar una enérgica represión física, también afectaba a los artículos 4, 5, 6, 9 y 13 de la Constitución, que regulaban el derecho de los ciudadanos a no ser detenidos sino en los casos y las formas establecidos en las leyes, el habeas corpus, la inviolabilidad del domicilio, y las libertades básicas de residencia, expresión, reunión y asociación, además del derecho de petición.

Durante los años 1870 a 1880, arreció la polémica respecto a si, en circunstancias de gravedad excepcional, la autoridad militar podía declarar unilateral y discrecionalmente el estado de guerra o debía esperar a que la autoridad gubernativa resignase el mando de forma expresa. Normalmente, los gobernadores civiles se escudaban tras del artículo 11 de la Ley Provincial de 2 de octubre de 1870 (art. 21 de la Ley Provincial de 29 de agosto de 1882), el artículo 12 de la Ley de Orden Público y la Real Orden del Ministerio de la Gobernación de 17 de enero de 1873 para advertir que sólo podía declararse el estado de guerra cuando la autoridad civil considerase llegado el momento de resignar el mando voluntariamente. Pero los capitanes generales consideraban absurdo que, hasta ese instante, las fuerzas de una guarnición estuvieran a las órdenes exclusivas de un gobernador civil reticente, por tozudez o indecisión, a ceder sus responsabilidades a los militares. Los altos mandos entendían que, en circunstancias de extraordinaria gravedad, era preciso aplicar el artículo 13 de la Ley de Orden Público, que otorgaba a la autoridad militar la potestad de declarar unilateral y discrecionalmente el estado de guerra. Esa argumentación se basaba en la denuncia del empleo abusivo del Ejército en cometidos policiales ajenos a su naturaleza, pero ocultaba la ambición de una completa autonomía castrense respecto de la autoridad gubernativa, en consonancia con su secular vocación de guardián del orden interior.

Una Real Orden Circular de Gobernación, emitida el 10 de agosto de 1885, trató de definir los límites de las atribuciones respectivas, y alentar la mutua colaboración entre las autoridades civiles y militares en caso de amenaza para la seguridad del Estado. Según esta normativa, correspondía a los gobernadores civiles restablecer la tranquilidad pública, utilizando para ello al cuerpo armado de Seguridad y a la Guardia Civil, y requiriendo si era preciso el apoyo de las autoridades judicial y militar. Sin embargo, no dependía exclusivamente del gobernador el reconocimiento de la insuficiencia de medios para mantener el orden - con la consiguiente cesión del mando a las autoridades castrenses-, ya que, de acuerdo con el citado artículo 13 de la Ley de Orden Público, cuando los amotinados hostilizasen a las fuerzas del Ejército, la autoridad militar tomaría el mando aun sin haberlo resignado la autoridad civil. Si no hubiera acuerdo previo, el estado de guerra sería declarado con carácter provisional, tal como, de hecho, sucedió en Barcelona en la «Semana Trágica» de julio de 1909. En los casos en que fuera posible adoptar un acuerdo, la convocatoria de la Junta de Autoridades correspondería al gobernador civil. Por último, la reunión de esta Junta con el objeto de levantar el 
estado de guerra, con arreglo al artículo 32 de la Ley de Orden Público, correspondía convocarla a la autoridad militar. Con la aplicación de este peculiar modus operandi en la asunción de funciones represivas en caso de conflicto, el Ejército obtuvo una virtual carta blanca en los trances graves de orden público, rebasando las atribuciones de decisión y fiscalización de las autoridades gubernativa y judicial, y otorgando a los militares la última palabra en lo referente al plazo de finalización de la situación excepcional. El conflicto de competencias volvería a aparecer una y otra vez hasta bien entrado el siglo XX, pero el Ejército no cesó de aumentar sus prerrogativas en el delicado ámbito del orden público ${ }^{23}$.

Además de los códigos constitucionales, otras leyes pueden influir en el control de la protesta. Dejando a un lado estos claroscuros del Texto Fundamental, la batería de medidas legales que el régimen desplegó para prevenir o castigar la comisión de atentados contra la seguridad pública resultó de una amplitud y un alcance abrumadores. Como en otros dominios, la Monarquía restaurada utilizó en su provecho la normativa ya existente. El Código Penal de 1870 establecía condenas de reclusión perpetua a muerte para los regicidas consumados o frustrados (arts. 153, 155 y 156); penas de confinamiento, destierro y relegación temporal en delitos contra las Cortes y el Consejo de Ministros (arts. 166-180), y penas de reclusión temporal en su grado máximo a muerte para delitos contra la forma de Gobierno (arts. 181-187). También se tipificaron escrupulosamente las infracciones del orden público. El delito de rebelión (arts. 243-249) se aplicaba a «los que se alzaren públicamente y en abierta hostilidad contra el Gobierno", mientras que el delito de sedición (arts. 250-256) atañía a «los que se alzan pública y tumultuariamente para conseguir por la fuerza, o fuera de las vías legales» la no promulgación de leyes; impedían la celebración de comicios y el libre ejercicio de las funciones de la autoridad, alentaban a la venganza contra las mismas y despojaban de sus bienes con un objeto político o social a personas, municipios, provincias o al Estado. El delito de atentado contra la autoridad (arts. 263-265) incluía aquellas acciones de fuerza englobadas dentro de los delitos de rebelión y sedición, pero que no supusiesen un alzamiento en armas de carácter público. El delito de desacato, insultos, injurias y amenazas a la autoridad (arts. 266-270) defendía a ministros, autoridades y funcionarios de las amenazas, calumnias o injurias de palabra o de hecho. Por último, el delito de desórdenes públicos (arts. 271-276) se refería a la perturbación del orden en los actos masivos, colegios electorales, espectáculos o centros productivos.

En un proceso crecientemente acelerado de transformaciones sociales como el que sufrió la España de la Restauración, no resultó extraño un cambio en la actitud del Estado ante la protesta. En un principio, el sistema político sólo se preocupó de recomponer el consenso entre las diversas fracciones el liberalismo decimonónico, roto durante el Sexenio, y de marginar políticamente a los diversos movimientos populares (republicanismo, obrerismo, carlismo), realizando un empleo abusivo del

${ }^{23}$ Sobre toda esta polémica, véase GONZÁLEZ CALLEJA, La razón de la fuerza, pp. 33-36. 
estado de excepción. A fines de siglo, el régimen ensayó una tímida apertura. De la prohibición de las asociaciones de trabajadores y de las huelgas como sedición que debía ser tratada por los tribunales militares, en los años setenta se pasó al reconocimiento legal de los derechos sindicales a través de la Ley de Asociaciones de 1887 y la Ley de Huelgas de abril de 1909. Con todo, la aparición del terrorismo anarquista impuso que el 10 de julio de 1894 y el 2 de septiembre de 1896 se promulgaran sendas leyes sobre represión de delitos cometidos por medio de explosivos. Por Real Orden de 15 de septiembre de 1896 se creó una Sección de la Policía Judicial especializada en la investigación y represión de los delitos sociales, especialmente los de carácter ácrata, en Madrid y Barcelona. El desarrollo del ciclo terrorista finisecular impuso un progresivo desarme de los mecanismos legales de garantía: el artículo 2. ${ }^{\circ}$ del Real Decreto de 16 de septiembre 1896, que daba instrucciones a los gobernadores civiles para la aplicación práctica de la Ley, preveía que las facultades gubernativas para la supresión de periódicos y centros anarquistas y el extrañamiento de sus propagandistas y afiliados sólo se desplegaran en las provincias de Madrid y Barcelona, pero acabaron extendiéndose a todo el territorio nacional por Real Decreto de 12 de agosto de 1897, es decir, inmediatamente después del asesinato de Cánovas. En el conjunto de España, las leyes antianarquistas no tuvieron especiales repercusiones de orden punitivo, pero en Barcelona fueron la cobertura ideal para una acción policial abusiva e indiscriminada que desembocó en los «procesos de Montjuïc» de fines de 1896. La denominada «Ley antianarquista» fue rectificada el $1 .^{\circ}$ de diciembre de 1896 , pero siguió aplicándose tres años más, y a partir de entonces mediante sucesivas prórrogas anuales hasta su definitiva derogación con el Gobierno Silvela en 1902, momento en que volvió quedar plenamente vigente la Ley de 1894, que en ningún momento había sido suspendida.

\section{LA TORTUOSA MODERNIZACIÓN DE LA FUNCIÓN POLICIAL}

Tras el tumultuoso cambio de siglo, los Gobiernos abordaron la siempre pospuesta tarea de la reforma policial. Como ministro de la Gobernación en el gabinete Silvela de fines de 1902, Maura abordó un ambicioso programa de reformas de la Policía, que se simultanearon con medidas puntuales de orden público. En marzo de 1903 se redactó un proyecto de Reglamento para una Ronda Volante de Vigilancia. Al mes siguiente, en pleno período electoral, se establecieron plazos de detención gubernativa no superiores a 24 horas, y se incitó a los gobernadores civiles a mantenerse en contacto permanente con las autoridades militar y judicial, y a utilizar a los agentes de Vigilancia y municipales antes que a la Guardia Civil en la represión de las agitaciones ${ }^{24}$. En diciembre de 1903, García Alix abordó la reorga-

${ }^{24}$ Los plazos de detención gubernativa, en la Circular confidencial de la Subsecretaría del Ministerio de la Gobernación (18-IV-1903), en Archivo de la Fundación Antonio Maura (AFAM), Archivo Antonio Maura, Correspondencia oficial, leg. 441, exp. n. ${ }^{1}$ y Archivo Histórico Nacional (AHN), Gobernación, Se- 
nización de la Policía gubernativa mediante un Proyecto de Reglamento Orgánico de Policía Especial para la vigilancia del personal anarquista, que se complementó en 1905 con una Real Orden para la organización y aumento de la Policía Gubernativa de Barcelona, en cuyo seno se creó una Sección de Policía de Seguridad $^{25}$. Con estas reformas se trató de centralizar las actividades policiales y dar estabilidad a los funcionarios, cuyos nombramientos y ceses serían en adelante decretados por el Ministerio de la Gobernación a propuesta del gobernador civil correspondiente. Se instituyó también un control administrativo sobre la conducta de estos agentes y un Registro Central de sospechosos en materia criminal y de reclamados por las autoridades. Por último, se intensificó incluso al más alto nivel la ya estrecha relación existente entre la Policía española y las instituciones similares en el extranjero, como la Sûreté francesa, especialmente en lo relativo a la información mutua sobre actividades anarquistas ${ }^{26}$.

Con el recrudecimiento de las explosiones de bombas en Barcelona en 190406, se especuló con una reactivación de la Ley antiterrorista de 1894 o 1896 y la ampliación de las plantillas policiales en Barcelona. El 4 de mayo de 1905, otro Decreto reglamentó el régimen y servicio de la Policía Gubernativa fuera de la capital. En este caso, la Policía dependería única y exclusivamente de los gobernadores civiles, que tendrían mando directo sobre los jefes provinciales de Seguridad y Vigilancia y dispondrían «la ejecución de los servicios de Policía en el territorio de su mando, bajo su responsabilidad» (art. 7) ${ }^{27}$. Llegados al poder a mediados de 1905 , los liberales tampoco se mantuvieron a la zaga en los proyectos de reforma policial28: el 22 de enero de 1906, un Real Decreto creó y reglamentó de forma definitiva la Policía gubernativa ${ }^{29}$.

Tras el hallazgo el 13 de febrero de 1906 una bomba en el Llano de La Boquería $^{30}$, Romanones logró aprobar el 20 de marzo una ley que preveía reformas

rie A, leg. 33A, exp. n. 10 y leg. 44A, exp. n. ${ }^{\circ}$. La Circular a los gobernadores civiles de misma fecha, en AHN, Gobernación, Serie A, leg. 44A, exps. n. ${ }^{\circ}$ s 21 y 22.

25 «Proyecto de Reglamento Orgánico de Policía Especial para la Vigilancia del personal anarquista y Real Decreto reglamentando la Policía Gubernativa» (AHN, Gobernación, Serie A, leg. 44A, exp. n. ${ }^{\circ} 20$ ) y borrador de Real Decreto sobre reforma de la Policía Gubernativa, 1903 (AFAM, Archivo Antonio Maura, Correspondencia oficial, leg. 171, carp. n. ${ }^{\circ}$ 1). Real Decreto sobre organización y aumento de la Policía Gubernativa en Barcelona, creando una Sección de Policía de Seguridad (4-V-1905), en AHN, Gobernación, Serie A, leg. 63A, exp. n. ${ }^{\circ} 16$.

${ }_{26}$ Carta personal del ministro de la Gobernación, Maura, al Directeur de la Sûreté Générale (1903), en AFAM, Archivo Antonio Maura, Correspondencia oficial, leg. 172, carp. n. ${ }^{\circ}$ 1. La intensificación de la vigilancia queda en evidencia por el cuaderno con centenares de filiaciones de «Anarchistes de nationalité Espagnole» enviado por la Policía gala hacia 1902-1903 (Archivo General de la Administración, Asuntos Exteriores, Embajada en París, caja n. ${ }^{\circ}$ 5832).

27 Emilio CASAL DE NIS, Consultor del policía. Estudios jurídicos, Madrid, Impta. de Fortanet, 1913, pp. LXVIII-XCII y Antonio VIQUEIRA HINIJOSA, Historia y anecdotario de la policía española, 1833-1931, Madrid, San Martín, 1989, p. 89. Otras normas policiales emitidas por esas fechas fueron los Reales Decretos de 22-I, 8-V y 29-IX y las Reales Órdenes de 31-III y 8-X-1905.

28 GONZÁLEZ CALLEJA, La razón de la fuerza, pp. 352-354.

29 «Reglamento de régimen y servicio de la Policía Gubernativa creada por Real Decreto de 22-I1906» (AHN, Gobernación, Serie A, leg. 63A, exp. n. ${ }^{\circ} 17$ ).

30 Véase Diario de Barcelona, 14 y 15-II-1906. 
radicales en la Policía de Barcelona, Gerona, la frontera francesa, el campo de Gibraltar y en la Sección de Investigación, revocando a todos sus jefes, aumentando las plantillas, trasladando la Policía Judicial o «de anarquistas», dependiente hasta entonces del Ministerio de Justicia, al dominio del ministro de la Gobernación, y estableciendo varios organismos jerárquicos. El remedio que proponía era una mayor profesionalización de los agentes, que verían garantizada su estabilidad laboral y aumentadas sus retribuciones, pero a los que se exigiría para su ingreso enel cuerpo condiciones probadas de aptitud y moralidad, mediante su cualificación en una Escuela de Policía similar a la creada en Madrid por Real Decreto de 19 de enero anterior. Sin embargo, el primer ministro Moret hubo pronto de prestar atención preferente a las presiones militares que desembocaron en la Ley de Jurisdicciones de 23 de marzo de 1906, por la que las injurias a las Fuerzas Armadas o los ataques contra la unidad nacional serían juzgadas en lo sucesivo por la autoridad militar $^{31}$. La decisiva intervención del Ejército contra los movimientos huelguísticos de 1901 a 1903 había conducido a esta situación que, como señala Ballbé, era «el final -o mejor el principio del fin- de un Estado constitucional Liberal construido sobre la bases de una militarización de la Administración pública y de las técnicas jurídicas para mantener el Orden Público»32.

El 8 de mayo se hizo público un Reglamento de régimen y servicio de la Policía Gubernativa en Barcelona, frontera francesa y Campo de Gibraltar. Dicha Policía estaría a las órdenes del gobernador civil, y en su nombre del Jefe superior de Policía de Barcelona, el cual centralizaría bajo su mando los servicios de Vigilancia y Seguridad (art. 6). Se creaban diez Secciones de Distrito y una Junta Superior de Policía en Barcelona (arts. 43-44), convocada por el Gobierno y compuesta por el gobernador, el alcalde y el presidente de la Diputación, que trataría de las faltas graves cometidas por los funcionarios policiales. El Reglamento también preveía la creación de las «comisiones de vecinos» (arts. 47-48) para comentar la marcha del servicio de orden público y coordinar la vigilancia callejera con las autoridades ${ }^{33}$. También se daban las normas para la creación de un Comité Superior de Policía de Barcelona (arts. 45-46), de carácter consultivo y destinado a apoyar las medidas excepcionales que el gobernador arbitrase para la reforma del servicio metropoli-

${ }^{31}$ Las circunstancias previas y el debate de la Ley de Jurisdicciones, en Manuel ÁLVARO DUEÑAS, «Poder militar y práctica política en el reinado de Alfonso XIII. De la suspensión de garantías constitucionales en Barcelona a la Ley de Jurisdicciones, 1905-1906 ", Revista de Estudios Políticos, n. ${ }^{\circ} 65$, julio-septiembre 1989, pp. 265-283; Joaquim de CAMPS Y ARBOIX, Història de la Solidaritat Catalana, Barcelona, Destino, 1970, pp. 47-56; Fernando SOLDEVILLA, El año político. 1906, Madrid, Impta. de Ricardo Rojas, 1907, pp. 15-17, 35-41, 52, 61-64, 67-68, 72-82, 84-110, 117-123, 138-145, 162-165, 174-174 y 233-241; carta del embajador italiano Silvestrelli de 15-III-1906 en Archivio Storico del Ministero degli Affari Esteri (ASMAE), Serie Politica «P», Spagna (1903-1906), caja 74 y documentación depositada en National Archives, Foreign Office (NA.FO), leg. 371/134, pp. 1-16. Véase también Ricardo LEZCANO, La Ley de Jurisdicciones, 1905-1906 (una batalla perdida por la libertad de expresión), Madrid, Akal, 1978.

32 BALLBÉ, Orden público y militarismo, p. 279.

${ }^{33}$ Reglamento para el régimen y servicio de la Policía Gubernativa (8-V-1906), cit. en CASAL DE NIS, Consultor del policía, pp. L-LXVII. 
tano de orden público. Sin embargo, este Comité, compuesto por el gobernador civil, el presidente de la Diputación, el alcalde de Barcelona y el presidente de la Cámara de Comercio, acabaría convirtiéndose en los años siguientes en la palestra de los intereses encontrados de las diversas «fuerzas vivas» de la ciudad condal. Figueroa realizó una serie de nombramientos sin consultar con el gobernador, quien, desautorizado, aplazó sine die la reforma policial y presentó su dimisión a inicios de junio de $1906^{34}$.

Tras el atentado de Morral, el gabinete López Domínguez trató de dar un nuevo impulso a la reforma de los medios represivos del Estado iniciada por su antecesor. A mediados de septiembre, aún al calor del reciente atentado de la calle Mayor, el ministro de Gracia y Justicia, conde de Romanones, reiteraba en las Cortes la necesidad de reprimir severamente el anarquismo mediante leyes de marcado carácter punitivo. Pero las medidas judiciales propuestas por Figueroa no lograron la aquiescencia del gobernador Francisco Manzano, partidario de la aplicación enérgica de la Ley antianarquista de 1896 y de la cooperación con los gobiernos extranjeros ${ }^{35}$.

Los nuevos gobernantes conservadores se mostraron decididos a sujetar firmemente las riendas del orden público, poniendo en vigor una gran parte de las medidas de reforma «aparcadas» por los gabinetes liberales. La Cierva se aprestó a cortar radicalmente con los vicios clientelares, y a abordar en serio la profesionalización de la Policía. Acometió una draconiana depuración de funcionarios (350 de un total de 500) y una profunda reorganización de los servicios, comenzando en Reglamento para los funcionarios de la Policía Gubernativa destinados a Madrid que fue promulgado el 27 de febrero de 1908, y que confirmaba la dependencia de la Policía respecto del gobernador civil $^{36}$. La culminación lógica del paquete de medidas propuesto fue la presentación el 10 de febrero de 1908, y la promulgación el 28 de ese mes, de una Ley Orgánica de la Policía Gubernativa de Madrid, que estableció oficialmente la distinción entre los Cuerpos de Vigilancia y Seguridad, y su supeditación a las órdenes del gobernador civil de la provincia (art. 1). Al frente de las comisarías de distrito se colocó a capitanes del Cuerpo de

${ }^{34}$ La reorganización de la Policía antianarquista de Barcelona, en documentación depositada en Archivo General de Palacio (AGP), caja 13.177. La andadura de la Junta y del Comité Superior de Policía de Barcelona, en «Policía Gubernativa», Anuario Estadístico de la ciudad de Barcelona, tomo VI, 1907, Barcelona, Impta. de Henrich y Cía., 1909, pp. 216-219 y Anuario Estadístico de la ciudad de Barcelona, tomo VII, 1908, Barcelona, Impta. de Henrich y Cía., 1910, pp. 149-151.

35 Véanse las cartas de Francisco Manzano a Alfonso de Aguilar, especialmente la de 4-VIII-1906, donde opina que las medidas judiciales de Romanones no pasarían del nivel de proyecto, en AGP, caja 13.240, exp. n. ${ }^{\circ} 4$.

36 CASAL DE NIS, Consultor del policía, pp. XIII-XLIX y Real Decreto de 9-IX-1907 sobre reorganización de la Policía gubernativa de Madrid (Gaceta de Madrid, n. 254 de 11-IX-1907, pp. 1.065-1.066). Un repaso sumario a las reformas policiales abordada por la Cierva, en José MARTíNEZ RUIZ, La Cierva, por Azorín, Madrid, Impta. Sucesores de Hernando, 1910, pp. 15-18. El nuevo «estilo Cierva» en el Ministerio de la Gobernación, en María Jesús GONZÁLEZ HERNÁNDEZ, El universo conservador de Antonio Maura. Biografía y proyecto de Estado, Madrid, Biblioteca Nueva/Fundación Antonio Maura, 1997, pp. $182-183$ y 216-217. 
Seguridad, cuya oficialidad procedía en su mayor parte de la Guardia Civil ${ }^{37}$. El 11 de abril se hizo público el reglamento definitivo del Cuerpo de Seguridad y Vigilancia para toda España, que estaría vigente hasta la profunda remodelación del Cuerpo emprendida noviembre de 1930 por el general Mola.

Las disposiciones continuaron apareciendo sin respiro en la Gaceta durante los años 1907 y 1908: se regularon los ascensos en la Guardia Civil, se extendió el Cuerpo de Seguridad a las capitales y poblaciones importantes de catorce provincias, se conectó telegráfica y telefónicamente a todos los Gobiernos Civiles con el Ministerio de la Gobernación, se contrataron instructores extranjeros para el perfeccionamiento científico de la Policía, y se aumentó el número de agentes de servicio y de guardias civiles en ciudades como Barcelona. Las reformas en el aparato judicial siguieron la tendencia a reducir la participación popular en las vistas por delitos políticos, según la tónica marcada por Maura en su reforma de diciembre de 1904 de la Ley de Explosivos de 1894. Por otra parte, permitió que el número de agentes que prestaban servicio en Barcelona se ampliara a 400 en 1907, 540 en 1908 y 800 en abril de $1909^{38}$. En Barcelona, el gobernador Ángel Osorio y Gallardo abordó la transformación de un cuerpo policial poco profesional, corrupto, infradotado, desarticulado y desmoralizado: se determinaron las atribuciones de jefes e inspectores en relación con los gobernadores civiles, el personal fue depurado, los salarios fueron incrementados, la estabilidad en el empleo garantizada, y los archivos y registros de todas las oficinas policiales comprobados, revisados y reordenados mediante índices por papeletas según el sistema utilizado

37 Real Orden del Ministerio de la Gobernación (12-VII-1909) participando que es conveniente que el Cuerpo de Seguridad fuera mandado por jefes, oficiales y subalternos de la Guardia Civil, de acuerdo con el art. 9..$^{\circ}$ de la Ley de 27-II-1908. La respuesta del jefe de la Sección de Instrucción, Reclutamientos y Cuerpos Diversos del Ministerio de la Guerra, Miguel Gistau Parrondo (2-IX-1909), consideraba inconveniente esta medida, pues ampliaría desmesuradamente las escalas de esas clases (Archivo General

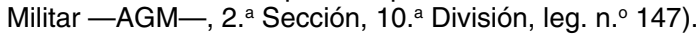

${ }_{38}$ AHN, Gobernación, Serie A, leg. 2A, exp. n. ${ }^{\circ} 15$; Juan de la CIERVA Y PEÑAFIEL, Notas de mi vida, Madrid, Instituto Editorial Reus, 1955, p. 101 y Antonio ROMERO MAURA, «Terrorism in Barcelona and its impact on Spanish politics, 1904-1909", Past \& Present, n. ${ }^{4}$ 41, diciembre 1968, p. 170. Según el diputado Rafael M. ${ }^{a}$ de Labra, en una ciudad como Barcelona, que contaba con 650.000 habitantes, había 703 agentes y un presupuesto de 966.000 pts. para servicios de Policía, mientras que en Madrid, con una población de unas 580.000 almas, se desplegaban 1.802 policías que contaban con un fondo de 2.216.000 pts. para sus actividades (Diario de Sesiones, Congreso de los Diputados, 27-VI-1907, p. 18). A fines de II-1908 se incrementaron sustancialmente las fuerzas de la Guardia Civil, y se hablaba también de un proyecto de ley que posibilitara el aumento de la plantilla en 160 guardias de Seguridad y unos cien agentes e inspectores, además de un incremento oficioso de confidentes y auxiliares (telegrama a Ossorio, 25-II-1908). El gobernador civil de Barcelona afirmó que se necesitaba más de un millar de guardias de Seguridad para garantizar el orden público en la ciudad, e incluso sugirió el reclutamiento de confidentes entre las mujeres y los hijos de los propios guardias (telegrama de Ossorio al ministro de la Gobernación, 26-II-1908, ambos documentos en AHN, Gobernación, Serie A, leg. 60A, exp. n. ${ }^{\circ}$ 10). La situación cambió significativamente en los años siguientes, ya que el diputado radical Hermenegildo Giner de los Ríos declaró en las Cortes el 14-IV-1909 que los efectivos de Policía y Guardia Civil en Barcelona ascendían a 7.224 hombres, y contaban con un presupuesto de 850.000 pts. En efecto, en el presupuesto de 1908 se aumentó una compañía de 140 hombres, con sus oficiales correspondientes, y un escuadrón de cien caballos. Por Ley de 3-IV-1908, que puso en marcha la Jefatura Superior de Policía de Barcelona, se creó otra compañía de 160 hombres, y en los presupuestos de 1908 se aumentaron las fuerzas de Seguridad en otro centenar de agentes. 
por la Prefectura de París. Se puso a punto un servicio de investigación por barrios, la Escuela de Policía (cuyos exámenes de ingreso presidía el propio Ossorio ${ }^{39}$ ), el escuadrón de Seguridad, la vigilancia del mar, y se redactaron los reglamentos de servicio de cada dependencia y negociado. A inicios de 1908 se creó un cuerpo de Policía especial para la represión del terrorismo a las órdenes directas del gobernador, y se nombró un jefe de Policía para toda la ciudad. Ossorio fue especialmente inflexible en la erradicación de la tortura y en el tratamiento de casos de corrupción como los protagonizados por los viejos inspectores Antonio Tressols (a) Vinagret y Antonio Ramírez (a) Memento, especializados en malos tratos y chantajes a criminales, o el doble juego provocador de hombres como el teniente Morales (comprometido en octubre de 1903 en la colocación de bombas que luego fingía descubrir) o la «banda» del confidente Joan Rull i Queraltó ${ }^{40}$.

La incapacidad de la autoridad gubernativa para poner coto a las bombas alentó un proyecto de privatización de los servicios policiales patrocinados por el Ayuntamiento y la Diputación. La Oficina de Investigación Criminal (OIC) creada en el verano de 1907 bajo el asesoramiento del inspector de Scotland Yard Charles Arrow se vio frustrada por la falta de apoyo del Gobierno, la rivalidad con la Policía local y la abierta hostilidad de anarquistas y republicanos, que iniciaron una campaña en su contra. En último término, la OIC entró en decadencia con el reforzamiento de la plantilla y medios de la Guardia Civil y la Policía de Seguridad (se creó una Comisaría General) a inicios de 1908, las desavenencias de Arrow con Prat de la Riba y los puentes tendidos con Maura para sacar adelante el proyecto de Ley de Administración Local, y desapareció a fines de agosto de 1909 minada por el desprestigio al no haber sabido prevenir la Semana Trágica y no servir ya como moneda de cambio con el gabinete Maura ${ }^{41}$.

Entretanto, la situación en Barcelona había alcanzado tal grado de crispación que Maura creyó llegado el momento de impulsar un paquete definitivo de medidas legales contra el anarquismo. El 24 de enero de 1908 presentó ante el Congreso un proyecto de Ley que adicionaba a la Ley de 10 de julio de 1894 sobre atentados por medio de explosivos un único artículo, que autorizaba al Gobierno, a petición de las autoridades de la provincia afectada, a suprimir publicaciones y centros considerados como anarquistas, y a expulsar del Reino a las personas que, de palabra o por escrito, propagasen ideas ácratas o formaran parte de asociaciones de ese cariz. Estos individuos corrían el riesgo de purgar largos años de cárcel en caso de retorno, y se establecía la posibilidad de crear una Sala Especial para procedi-

39 Sobre la Escuela de Policía de Barcelona, creada por el artículo 16 del Real Decreto de 22-III-1906 y abierta el 1-IX-1907 con medio centenar de aspirantes que eran instruidos en sus horas libres de servicio sobre legislación, práctica de servicios, fotografía, gimnasia, esgrima y avances de la Policía científica, como dactiloscopia o señalamiento descriptivo, según el sistema de portait parlé de Alphonse Bertillon, véase «Policía Gubernativa», Anuario Estadístico de la ciudad de Barcelona, tomo VI, 1907, Barcelona, Impta. de Henrich y Cía., 1909, pp. 218-219.

40 La mejor semblanza de Rull y su época, en Antoni DALMAU, El cas Rull. Un traficant del terrorisme a la ciutat de les bombes (1901-1908), Barcelona, Columna Edicions, 2007.

41 GONZÁLEZ CALLEJA, La razón de la fuerza, pp. 402-417 y 438-439. 
mientos especiales contra el terrorismo. La «Ley de Represión del Terrorismo» no contemplaba, por tanto, una amplia reforma del Código Penal, sino que era una simple enmienda de una normativa preexistente ${ }^{42}$, pero en la caldeada atmósfera generada por el «caso Rull» y el asesinato del rey y el príncipe heredero de Portugal, generó en la izquierda, desde la dinástica al movimiento obrero, una verdadera atmósfera de repulsa. Las concepciones respecto al orden público - hasta entonces igualmente autoritarias sea cual fuere el color del partido turnante-comenzaron a acentuar las divergencias políticas entre unos liberales partidarios de una actitud más benévola, recurriendo a la suspensión preventiva de garantías constitucionales, el estado de guerra, las medidas de gracia o las reformas de la Policía, y un partido conservador en el que hombres como Maura o la Cierva no dudaban en criticar públicamente esta supuesta lenidad e impulsaban medidas policiales más expeditivas que satisficieran a sus bases caciquiles rurales y a la opinión ultracatólica en la cual se apoyaban de manera cada vez más ostensible. La ley fue aparcada a inicios de junio de 1909, cuando entró en el candelero Ley de Administración Local, pero para ese entonces el Gobierno conservador estaba enfrascado en la más profunda reorganización de los servicios de Policía realizada hasta la fecha. Sendos Reales Decretos de 3 de abril y 28 de diciembre de 1908 dispusieron la creación de las Jefaturas Superiores de Policía de Barcelona y Madrid, cuyo control especializado de las cuestiones de orden público y su control de los Cuerpos de Seguridad y Vigilancia representan el inmediato precedente del establecimiento de la Dirección General de Seguridad (DGS) en 1912.

Además del significativo aumento de los presupuestos globales para Seguridad y Vigilancia ${ }^{43}$, se aplicó una inyección presupuestaria a las Jefaturas Superiores, se

42 Presentación por el ministro de Gracia y Justicia de dos proyectos de Ley, prolongando la suspensión del juicio por Jurado en Barcelona y Gerona acordada por Real Decreto de 4-II-1907, y adicionando la Ley de 10-VII-1894 (DSC, Senado, 24-I-1908, pp. 2.903-2.904). El artículo único de la «Ley antiterrorista», en Gabriel MAURA GAMAZO y Melchor FERNÁNDEZ ALMAGRO, Por qué cayó Alfonso XIII. Evolución y disolución de los partidos históricos durante su reinado, Madrid, Eds. Ambos Mundos, 1948, pp. 122-123. El dictamen de la Comisión del Senado, presidida por Canalejas, acerca de ese pro-

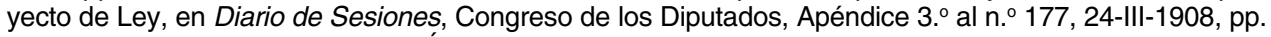
1-2. Véase también Eduardo COMíN COLOMER, Historia del anarquismo español, Madrid, AHR, 1956, vol. I, pp. 216-218; GONZÁLEZ HERNÁNDEZ, El universo conservador de Antonio Maura, pp. 221-223 (quien califica la ley de «verdaderamente represiva»); Rafael PÉREZ DELGADO, Antonio Maura, Madrid, Tebas, 1974, p. 554; Fernando SOLDEVILLA, El año político. 1908, Madrid, Impta. de Ricardo Rojas, 1909, pp. 18-19; Pedro VOLTES BOU, La Semana Trágica, Madrid, Espasa-Calpe, 1995, pp. 78-79; Carlos SECO SERRANO, La España de Alfonso XIII. El Estado y la política (1902-1931). Vol. I: De los comienzos del reinado a los problemas de la posguerra, 1902-1922, tomo XXXVIII de la Historia de España Menéndez Pidal, dirigida por José M. ${ }^{a}$ Jover Zamora, Madrid, Espasa-Calpe, 1995, pp. 135-136 (quien achaca toda la resistencia contra la ley a la campaña del trust periodístico) y ROMERO MAURA, «Terrorism in Barcelona», pp. 179-180, quien considera estas medidas gubernamentales como razonables frente a la arbitraria acción de la Policía y la violenta represión. La postura de Ossorio y una visión bondadosa de la imagen autoritaria de Maura en este asunto, en Javier TUSELL, Antonio Maura. Una biografía política, Madrid, Alianza, 1994, pp. 102-103.

${ }_{43}$ El presupuesto para 1904 era de 1.370 .060 pts. para la Policía de Seguridad, de 2.040 .000 pts. para Vigilancia y 691.674 pts. para gastos anejos, lo que hacía un total de 3.868.734 pts. En 1909 las partidas se ampliaron a 3.745.835 pts. para el Cuerpo de Seguridad, 3.856.000 pts. para el de Vigilancia, 25.875 pts. para indemnizaciones y 1.271.607,50 para otros servicios. En suma, un total de $8.898 .317,50$ pts., que 
mejoraron los haberes de los agentes de la Policía y la Guardia Civil, se elevaron las categorías; se consolidaron la estabilidad en el puesto de trabajo y las pensiones, se creó la Escuela de Policía de Madrid y se condicionó el ingreso de nuevos funcionarios a un sistema de oposición más formulario que equitativo, con lo que lo que se siguió manteniendo el «enchufismo» y los tratos de favor. A pesar de las repetidas reformas de los cuerpos de Seguridad y Vigilancia, y de la mejora de sus comunicaciones con la Guardia Civil, las fuerzas de orden público contemplaron impotentes la evolución de la violencia política y común en las grandes ciudades, como lo atestiguó su sonoro fracaso a la hora de prevenir y reprimir los alborotos de la «Semana Trágica» barcelonesa.

A fines de 1912 Romanones trató de abordar una nueva reforma, en la línea de una creciente centralización ${ }^{44}$. En primer lugar, proyectó crear una Prefectura de Policía de Madrid según el exitoso modelo parisino, que asumiría el mando único de los Cuerpos locales de Vigilancia y Seguridad, con autoridad propia y facultades directamente delegadas del ministro de la Gobernación, sustrayendo al gobernador civil sus tradicionales atribuciones en materia de orden público ${ }^{45}$. Al mismo tiempo, un proyecto de Real Decreto pretendía refundir las Secciones de Vigilancia y Seguridad en un único Cuerpo de Policía Española, coordinado por una Dirección General de la Policía, dependiente del Ministerio de la Gobernación y dividido en cuatro Secciones: Policía de Seguridad, Policía Gubernativa, Policía Judicial y Policía Política, estas tres últimas extraídas del Cuerpo de Vigilancia. La idea de crear una instancia única de gestión policial centralizada había estado rondando por la cabeza de los responsables de orden público de los gobiernos liberales desde el año 1910, pero fue duramente criticada desde la izquierda por considerar excesivo el poder acumulado por este «superprefecto», que extendía sus tentáculos por todo el entramado del orden público ${ }^{46}$, y por la derecha por reducir las atribuciones de la Guardia Civil en materia de orden público, y por considerarla incompatible con las atribuciones dadas a las Jefaturas Superiores de Policía de Madrid y Barcelona, y con el poder que ostentaban tradicionalmente los gobernadores civiles como responsables últimos del orden público en sus respectivas demarcaciones.

El 25 de noviembre de 1912 -es decir, dos semanas después del asesinato de Canalejas- se promulgó un Real Decreto sobre reorganización del Cuerpo de Policía, que propiciaba un cierto avance civilista en materias de orden público. Gra-

más que doblaba la asignación presupuestaria del lustro anterior. Sobre este y otros aspectos de la reorganización de la Policía, véase despacho de Maurice de Bunsen a Edward Grey (Madrid, 24-I-1909), en NA.FO, leg. 371/741, pp. 26-30, que incluye un «Memorandum regarding the Spanish Police communicated confidentially by the Spanish Government» (23-I-1909).

${ }^{44}$ Ramón MÉNDEZ ALANís, La policía. Estudio científico-jurídico de la función, órgano y elementos de acción de la policía de Derecho o de Seguridad, por___, Madrid, R. Velasco, Imp., 1912.

${ }_{45}$ Informe acerca de la creación de una Prefectura de Policía de Madrid (s.f., pero de fines de 1912), en Real Academia de la Historia (RAH), Archivo Romanones, leg. 48, exp. n. ${ }^{\circ} 34$.

${ }_{46}$ Véase la crítica de Jerónimo Camarón, en El Liberal (Madrid), 7-I-1913, y un «Parte Principal sobre la reorganización de la Policía» (4-XII-1912) dirigido a Romanones donde descalifica el capítulo IX del libro de MENDEZ ALANíS, La policía, en RAH, Archivo Romanones, leg. 48, exp. n. ${ }^{\circ} 34$. 
cias a esta norma, el Gabinete liberal clausuraba las Jefaturas Superiores de Policía de Madrid y Barcelona establecidas en 1908, y creaba en su lugar la Dirección General de Seguridad, encargada de «la organización y ejecución de los servicios que comprende la Policía gubernativa para cuyo efecto se considerará ésta dividida en dos secciones: de Vigilancia y Seguridad». En su afán de coordinación de las actividades de Seguridad y Vigilancia, la nueva entidad policial heredaba el espíritu centralizador de la Dirección de Seguridad constituida en 1886. La DGS seguía estructurada en las tradicionales Secciones de Vigilancia y Seguridad, pero a pesar del empeño puesto para su control, la Guardia Civil quedó otra vez al margen de esta coordinación, y el desarrollo de una entidad civil y unificada de gestión policial no evitó la demasiado usual aplicación sistemática de soluciones castrenses a la agitación social. Aunque la DGS vio aumentar su presupuesto, se crearon brigadas especializadas de Investigación Criminal, Anarquismo y Socialismo e Información, y también se intensificó la vigilancia sobre los anarquistas, el Gobierno liberal puso un empeño no menor en incrementar la cooperación internacional en materia policial ${ }^{47}$, si bien la eficacia de las labores de represión y vigilancia en el exterior resultó siempre muy relativa.

Aún a fines de 1913, Romanones proyectaba una profunda reorganización de la Policía a escala nacional, con la creación de una Dirección General del Cuerpo Militar de Seguridad, la formación de un escalafón de jefes y oficiales, la unificación de haberes, escala gradual de recompensas, etc. Pero como en casos anteriores, no parece que la adopción de tales medidas fuera seguida de un éxito clamoroso. Las carencias materiales siguieron lastrando la eficacia de la función policial, y la persistencia de los problemas de orden público incrementó la desconfianza de algunos sectores sociales en la capacidad de coerción o persuasión de los agentes del poder civil. Como muestra de ello, ese mismo año 1912 la Asociación Patronal de Barcelona decidió reforzar su sección política con la creación de un escuadrón policial privado, denunciado por la CNT como una "cuadrilla de asesinos»48. Estas actitudes no eran sino los primeros vagidos de la lucha social que ensangrentaría las calles de la ciudad condal desde fines de la Gran Guerra, y cuya tipología violenta comenzaba a perfilarse en esos años.

\footnotetext{
47 Véanse la propuesta de la Direction de la Sûreté Générale Publique belga de mutua colaboración policial sobre tránsito de viajeros, transmitida por el embajador Alfonso Merry del Val (15-II-1913), y la respuesta positiva en Real Orden del subsecretario de Gobernación, Navarro Reverter, al Ministerio de Estado (28-V-1913). También eran frecuentes los viajes de policías españoles de la DGS a Hendaya, Burdeos, Cerbère y Montpellier con motivo de los viajes reales. Véase Ministerio de Estado a Embajador en París, 24-IV-1913. Estos documentos, en Archivo del Ministerio de Asuntos Exteriores, Sección Histórica, Política Interior, Orden Público, Parte General, 1911-1919, leg. H 2.753.

48 Stanley G. PAYNE, La revolución española, Barcelona, Argos, 1977, p. 53. Según Ángel PESTAÑA, Terrorismo en Barcelona (Memorias inéditas), Barcelona, Planeta, 1979, pp. 81-82, en 1913 Francisco Martorell, comisario jefe de la Policía de Barcelona, intentó organizar un grupo de confidentes sindicalistas para que atentasen contra sus compañeros, pero el plan fracasó al ser descubierto por la CNT.
} 


\section{EL DETERIORO DEL ORDEN PÚBLICO EN LA CRISIS DE LA RESTAURACIÓN}

Durante la agitación social y política posterior a la Gran Guerra, el Estado fue perdiendo el control de los ámbitos político, intelectual y económico, y hubo de acentuar su capacidad de respuesta, ya fuera mediante la cooptación o la represión. Pero su control, al hacerse más extenso, se hizo más difuso, y hubo de aceptar de grado o por fuerza una concurrencia social y corporativa en los asuntos del orden público que amenazó su propia autoridad. El sistema de control social de la Restauración sufrió un lento y progresivo desmoronamiento, marcado por la ineficacia para afrontar los nuevos modos de protesta sociopolítica, por la insubordinación de alguno de sus organismos esenciales de vigilancia pública (el Ejército), y por la retirada de confianza por parte de sectores significativos de la élite social dominante.

Las fuerzas políticas y sociales que vinculaban sus intereses a la pervivencia del régimen de la Restauración comenzaron a disentir crecientemente respecto del proyecto de Estado y del modelo represivo más adecuado para su defensa. Ello acentuó el aislamiento y la degradación de las instituciones de seguridad, además de su caída hacia actitudes de rebeldía corporativa (las más conocidas fueron las Juntas de Defensa) y su proclividad a soluciones políticas de naturaleza autoritaria ${ }^{49}$, que conectaron con las exigencias de determinados grupos conservadores aterrorizados con la inminencia de una «revolución bolchevique». Alarmados por esta amenaza más ficticia que real y por el vacío de autoridad estatal, los propios grupos sociales «de orden» y sus subordinados, que hasta entonces habían confiado su seguridad física a los instrumentos de control del régimen (Ejército, Policía, Justicia) vieron con alarma cómo el perfeccionamiento de los medios combativos del movimiento obrero, y su voluntad de convergencia con sectores mesocráticos ponían en evidencia la escasa fiabilidad de los medios coactivos oficiales. Por lo tanto, trataron de garantizar su supervivencia a través del apoyo al poder militar en detrimento del poder civil (primacía que había obtenido cierta institucionalización con la Ley de Jurisdicciones de 1906), la organización de policías paralelas (como la banda de Bravo Portillo a partir de 1919), la movilización creciente de los ciudadanos en armas (en 1902 se creó el Somatén en Barcelona, en 1909 se perfeccionó y en 1917-1918 alcanzó su apogeo, para extenderse luego a toda España como modelo de «guardia cívica» contrarrevolucionaria) y, por fin, el recurso al estado de excepción permanente con el apoyo al pronunciamiento de septiembre de 1923.

La huelga de La Canadiense de febrero-marzo de 1919 abrió el camino a la más aguda crisis de relaciones político-militares desde el pleito juntero de $1917^{50}$. Tras la expulsión del gobernador civil Carlos Montañés y del jefe superior de Poli-

49 Amadeu RECASENS, «Desenvolupament policial i societat a l'Europa del segle XIX», L'Avenç, n. ${ }^{\circ}$ 97, octubre 1986, pp. 40-45.

50 GONZÁLEZ CALLEJA, El máuser y el sufragio, pp. 127-140. 
cía Gerardo Doval en abril y la subsiguiente caída del gabinete Romanones, el Gobierno Civil se convirtió en una mera dependencia de la Capitanía General, lo que se tradujo en una militarización del orden público que sería imitada en otras provincias especialmente conflictivas. Una nueva crisis se produjo a inicios de enero de 1920, cuando tras el atentado al empresario Félix Graupera, el capitán general Joaquín Milans del Bosch declaró el estado de guerra con atribuciones excepcionales, lo que llevó a la ilegalización de la Confederación Regional del Trabajo de Cataluña el 23 de enero, pero el conflicto fue solucionado temporalmente con la destitución de Milans el 10 de febrero. Tras la explosión en el café Pompeya el 12 de septiembre de 1920, una nueva ofensiva de las «fuerzas vivas» y de la guarnición de Barcelona condujo el 8 de noviembre a la asunción del Gobierno Civil por parte del general Martínez Anido. A partir de ese momento se acentuó la beligerancia de la autoridad gubernativa en las querellas sociales, con una extensa aplicación de medidas ilegales como la «ley de fugas». Estos hábitos violentos y estas oscuras vinculaciones nos llevan al planteamiento de una cuestión primordial: si existió en la Barcelona de los primeros años veinte un verdadero «terrorismo de Estado", entendido como la capacidad del Gobierno para dirigir una guerra interna no declarada de una forma sistemática y sin cuartel contra un enemigo interior, utilizando los recursos extralegales a su alcance, como la delimitación imprecisa de los hechos delictivos y las medidas clandestinas de sanción estatal (homicidios, torturas, privación de la libertad o de la propiedad, etc.) sin las debidas garantías jurídicas $^{51}$. Resulta innegable que este tipo lucha antisubversiva se aplicó en diversa medida en la ciudad condal en los primeros años veinte, y especialmente durante el mandato de Martínez Anido, pero nunca constituyó el entramado de un sistema represivo estable, ya que entre fases de fuerte intervención violenta se intercalaron períodos de aparente normalidad, donde las relaciones cívicas y laborales trataron de canalizarse por la vía del acuerdo (cuadro 3). Más que a un régimen de terror sistemático impulsado desde las instancias gubernamentales, Martínez Anido recurrió esporádicamente al terror de Estado en medidas como la «ley de fugas» 0 los extrañamientos. Además, la adopción y el desarrollo de estas iniciativas no eran patrimonio exclusivo del Gobierno, sino que eran fruto de un acuerdo coyuntural entre organizaciones institucionales, sociales y políticas de diversa naturaleza, frecuentemente enfrentadas en sus estilos de actuación, pero a las que unía el afán por liquidar a un enemigo común. El terrorismo alentado o permitido por Martínez Anido no intentó en un primer momento acabar con el pistolerismo sindicalista, sino exacerbarlo para atraer a la órbita del Estado a fuerzas hasta entonces marginadas del mismo, como el catalanismo o el jaimismo, y que nunca antes habían pensado en implicarse en una cruzada antirrevolucionaria al lado del poder constituido ${ }^{52}$. Después vendría la eliminación indiscriminada del Sindicato Único,

51 Véase Ernesto GARZÓN VALDÉS, «El terrorismo de Estado (El problema de su legitimación e ilegitimidad)», Revista de Estudios Políticos (Nueva Época), n. ${ }^{\circ} 65$, julio-septiembre 1989, pp. 35-55.

52 Esta es una opinión expuesta por Ángel PESTAÑA, Confesiones de nuestro tiempo. Lo que aprendí en la vida, Madrid, Aguilar, 1933, p. 88. 
medida que se legitimaba con argumentos como la ineficacia de los resortes punitivos del Estado para acabar con la subversión, la imposibilidad de identificar a los terroristas o sus cómplices entre el conjunto de la masa obrera y la inevitable simetría de los métodos de lucha según el viejo adagio - compartido plenamente por el belicoso gobernador- de «en la guerra, como en la guerra». Pero dentro de la represión indiscriminada dirigida desde el Gobierno Civil de Barcelona no deja de resultar chocante que Martínez Anido actuara prioritariamente contra el sector más moderado de la CNT, diluyendo de esa manera la separación entre terroristas y sindicalistas, y obstaculizando por largo tiempo la posibilidad de establecer una solución negociada al problema.

La identificación absoluta de la estrategia represiva estatal con los intereses de los grupos sociales dominantes, especialmente la patronal y la burguesía catalanista, debe ser puesta en duda: a fases de enfrentamiento sucedieron alianzas coyunturales impuestas por el combate contra el cenetismo, dentro del cual era a veces muy difícil deslindar la acción laboral, el terrorismo reivindicativo y el puro delito común $^{53}$. El terrorismo policial no pareció ser un «invento» del Gobierno para dividir el catalanismo y atraerse a parte del nacionalismo moderado, ya que, por contra, lo que se produjo fue un divorcio creciente entre la burguesía catalana y el Ejecutivo, y un ascenso imparable del militarismo hasta el desenlace de septiembre de 1923. La llamativa independencia del gobernador había sido el resultado de un largo y tortuoso camino de presiones e imposiciones de las Juntas Militares de Defensa sobre el poder civil, que en época de Dato había consentido en situar a jefes militares de reconocido talante autoritario como máximas autoridades gubernativas de provincias especialmente conflictivas, como Valencia (el general Primo de Rivera de forma interina), Zaragoza (el coronel Coello) y Barcelona ${ }^{54}$. Las deficiencias del servicio policial y su incapacidad para prevenir y reprimir por sí mismo la agitación de posguerra estuvo en el origen de una aparente paradoja: la creciente militarización y privatización de los resortes del orden público.

A pesar de que, el 22 de julio de 1918, el Gobierno Nacional de Maura promulgase una nueva Ley de Bases de la Policía Gubernativa, la Policía arrastraba aún a inicios de la década de los veinte penurias de todo tipo en el orden personal y material. La creación de la Dirección General de Seguridad, de las Jefaturas de Policía de Madrid y Barcelona y de la Comisaría General del Cuerpo de Vigilancia había marcado el camino a seguir para la creación de un modelo policial moderno, de carácter nacional y centralizado. Pero la debilidad congénita de la Policía, su es-

53 PESTAÑA, Terrorismo en Barcelona, p. 52. Consideraciones sobre el «terrorismo de Estado» en época de Martínez Anido, en Fernando del REY REGUILLO, Propietarios y patronos. La política de las organizaciones económicas en la España de la Restauración (1914-1923), Madrid, Ministerio de Trabajo y Seguridad Social, 1992, pp. 523-524, quien reconoce su existencia en p. 617.

54 Informe de embajador Jean-Marie-Antoine Defrance al Quai d'Orsay, 7-VII-1921. A decir de este diplomático, Bugallal había manifestado reiteradamente su deseo de abandonar el Ministerio de la Gobernación ante las cartas de amenaza numerosas y precisas que recibía a diario de medios sindicalistas (Archives du Ministère des Affaires Étrangères, Quai d’Orsay, Série Z, Europe 1918-1929, Espagne, leg. 33, pp. 134-135). 
casa profesionalización, su crónica falta de medios y su creciente desmoralización por las precarias condiciones de vida y el exceso de servicios, no presentaban suficientes garantías para la prevención inicial de los tumultos, que mostraban una tendencia cada vez más preocupante a degenerar en vastos levantamientos de carácter subversivo. Para ejercer sus funciones específicas en un país con 21 millones de ciudadanos, la DGS disponía en 1920 de un presupuesto de sólo 20 millones de un total de 166 millones de pesetas asignados al Ministerio de la Gobernación, lo que suponía una cifra muy por debajo de la empleada, por ejemplo, en la vigilancia exclusiva de la ciudad de París. Se contaba con menos de cuatro millares de guardias de Seguridad, que sólo desempeñaban su servicio en las ciudades más importantes ${ }^{55}$. Las medidas de rigor adoptadas tras la muerte de Dato se completaron con un proyecto de reforma, centralización y refuerzo de la Policía Gubernativa dentro de los créditos vigentes. El Cuerpo de Vigilancia pasó a contar con 2.534 individuos y con un presupuesto anual de 11.507 .500 pts., y el de Seguridad con 5.603 agentes y con una asignación de 17.140 .500 pts. ${ }^{56}$. La Guardia Civil, que además de su labor permanente en el campo actuaba como verdadero «bombero» antisubversivo, a través de constantes concentraciones intimidatorias en los núcleos urbanos o sus aledaños, vio aumentar su presupuesto de 38 millones de pts. en 1909 a 97 millones en el bienio 1920-1921, debido sobre todo al aumento de las plantillas en varios millares de hombres ${ }^{57}$. A estas fuerzas habían de añadirse las policías municipales, los cuerpos regionales residuales (Miñones, Mossos d'Esquadra) e incluso los serenos y los porteros de finca, virtualmente militarizados durante el «gobierno largo» de Maura. Además, en casos de excepcional gravedad podía echarse mano del Ejército, a pesar de su creciente división entre «africanistas» y «junteros» y su más que patente distanciamiento del poder civil.

El asesinato de Dato, el agravamiento de la situación del orden público en Barcelona y los repetidos fracasos de una Policía cada vez más mediatizada por el poder militar y sometida a la concurrencia con otras instituciones paraestatales de «defensa social», indujeron a los gobiernos a arbitrar nuevas reformas judiciales y gubernativas. En abril de 1921 se debatió un proyecto de reforma del Código Penal donde se ampliaban las circunstancias del delito de conspiración, y se consideraban como agravantes la complicidad de una colectividad o asociación y la comisión del delito con un objetivo político o social, por odio o venganza a las autoridades o al Estado o para despojarles de sus prerrogativas y derechos. Se propuso también una reforma de la Ley de Enjuiciamiento, que preveía la aplicación del procedimiento especial de carácter sumarísimo en el caso de que concurriesen circunstancias agravantes que dieran carácter terrorista al delito que se juzgaba. Estas iniciativas, que fueron interpretadas por juristas y políticos progresistas (Jiménez de

55 REY REGUILLO, Propietarios y patronos, pp. 452-453 y 457-458 nota 8.

56 Autorización al Gobierno para reforzar la Policía Gubernativa, en Diario de Sesiones, Congreso de los Diputados, Apéndice 9 al n. ${ }^{\circ}$ 41, 20-IV-1921.Véase también Fermín SOLANA, Historia parlamentaria del socialismo. Julián Besteiro, 1918-1920, Madrid, Taurus, 1975, vol. II, p. 813 nota 1.

57 «Organización policial del Estado español», El Sol, 8-VIII-1922, p. 3. 
Asúa, Moneva y Puyol...) como un arma en manos del Estado y de la burguesía catalana contra el movimiento cenetista, acabaron siendo retiradas por un Gobierno poco dispuesto a suscitar una polémica que, como durante la época de Maura, uniese de nuevo a toda la izquierda parlamentaria.

Tras la muerte de Dato, una Ley el 14 de junio de 1921 hizo desaparecer la DGS y puso en su lugar una Dirección General de Orden Público, que quedaba encargada de todo lo referente a la seguridad ciudadana y a la administración del personal y servicios de la Policía Gubernativa ${ }^{58}$. Además de ensayar por primera vez la coordinación de la Policía Gubernativa con la Guardia Civil, la nueva ordenanza incrementó la centralización de las fuerzas de orden público, y confirmó la disminución de atribuciones de los gobernadores civiles. Pero la reforma supuso también un evidente retroceso del civilismo en tan delicada instancia del Estado, puesto que ratificaba el sometimiento del Cuerpo de Seguridad a la jurisdicción castrense y acentuaba la indefinición respecto a la sujeción al fuero civil y al militar del resto de los funcionarios policiales. El predominio del Ejército en las plantillas de los organismos encargados del orden público era un hecho arrastrado desde inicios de siglo ${ }^{59}$, pero se había acentuado con la crisis de posguerra, y en especial durante el Gobierno Dato, provocando tensiones internas en algunos Cuerpos e insubordinaciones que deben ser incluidas entre los fenómenos de protesta «juntera» que afectaron en esa época a ciertos organismos del Estado. La creación de la Dirección General de Orden Público no palió los males crónicos de la administración policial española. Las reformas no evitaron la generalización de una movilización defensiva de los sectores conservadores que había comenzado a hacerse presente desde fin de siglo, pero que ahora adquiría una intensidad y significado desconocidos. Alarmados por la extensión de esta «amenaza revolucionaria», los grupos «de orden» resucitaron en las ciudades, con el apoyo de organizaciones y asociaciones privadas y de las instancias oficiales, instituciones civiles de movilización armada inspiradas en movimientos europeos homólogos y en rancios antecedentes peninsulares. Las «uniones cívicas» proliferaron en casi toda Europa como reacción espontánea de los grupos sociales opuestos a la «amenaza bolchevique", que consideraban que los recursos coercitivos o conciliatorios del sistema liberal-parlamentario no les protegían de forma satisfactoria frente a una "oleada subversiva» que atacaba los mismos fundamentos de su poder y de su concepción del mundo. Las «uniones cívicas» protegieron actividades de esquirolaje y de sindicalismo amarillo, y se dispusieron no sólo a la defensa de la propie-

58 Ley y Real Decreto autorizando al Gobierno para reorganizar la Policía Gubernativa y determinar los derechos y obligaciones de sus funcionarios dentro de los créditos consignados en el presupuesto vigente (14-VI-1921), en AHN, Gobernación, Serie A, leg. 46A, exp. n. ${ }^{\circ} 13$. Véase también «Reorganización de la Policía Gubernativa», Revista Técnica de la Guardia Civil, n. ${ }^{137,}$ VII-1921, pp. 16-18 y Francisco AGUADO SÁNCHEZ, Historia de la Guardia Civil, Madrid, Ediciones Históricas/CUPSA/Ed. Planeta, 1983-1985, vol. IV, pp. 187-188.

59 Esta militarización resutaba patente en el Cuerpo de Seguridad, donde todos los jefes y oficiales procedían de la Guardia Civil y del Ejército (MORALES VILLANUEVA, Las fuerzas de orden público, $\mathrm{p}$. 146 y Administración policial española, Madrid, Ed. San Martín, 1988, p. 187). 
dad, sino incluso a exigir del Estado la restricción de los derechos obreros de huelga o manifestación ${ }^{60}$.

El último Gobierno Dato había implementado medidas como la Ley de 29 de abril de 1920 sobre tenencia y uso de armas, que instituía una "guía de pertenencia» que acreditase la posesión y el derecho al uso de instrumentos de defensa personal. Un Real Decreto de 15 de septiembre de 1920 había establecido los términos de aplicación de la norma, regulando la fabricación de armas bajo la supervisión de la Guardia Civil, y prohibiendo su venta, cesión o cambio de armas sin la presentación de la licencia o la adquisición de la guía. Estas medidas cautelares obstaculizaron notablemente el tráfico ilegal de armas cortas que hasta entonces había favorecido notablemente las actividades pistoleriles, e hizo disminuir significativamente el número de delitos cometidos. Otra Real Orden de 11 de octubre mantuvo el control policial sobre armas prohibidas o ilícitas como estoques, bastones o puñales ${ }^{61}$. Posteriormente, por Ley de 2 de agosto de 1923, se amplió esta fiscalización estableciendo sanciones más severas (de cuatro meses y un día de arresto a un año de prisión correccional) para los portadores de armas cortas de fuego sin licencia fuera del domicilio ${ }^{62}$. La Dictadura sistematizó este paquete de medidas, e intentó ampliarlas a las sustancias explosivas ${ }^{63}$.

El nuevo Gobierno conservador, presidido por Sánchez Guerra desde inicios de marzo de 1922, apostó por un paulatino retorno hacia posturas de moderación, y emprendió un ambicioso proceso de recuperación de la autoridad perdida en los años anteriores a manos de los militares. El 30 de marzo se restablecieron las garantías constitucionales suprimidas por Romanones tres años atrás, y se dejó en libertad a los jefes anarcosindicalistas presos o extrañados. Anido fue sustituido el 24 de octubre tras no garantizar la vida de Pestaña, mantener constantes tensiones con los catalanistas y la DGS, perder el apoyo de las juntas y urdir un atentado contra si mismo. Sin embargo, el nuevo Gobierno de concentración liberal no pido evitar el recrudecimiento de la agitación sociolaboral y del activismo anarquista desde mayo de 1923. Ello volvió a levantar el descontento de las fuerzas vivas catalanas contra el gabinete, y reactivó la tentación militarista, esta vez en la persona del capitán general Primo de Rivera, que se mantuvo durante esos meses en constante desavenencia con la autoridad gubernativa, lesionando aún más la ya demasiado cuarteada autoridad civil.

60 Sobre este fenómeno, véase Eduardo GONZÁLEZ CALLEJA y Fernando del REY REGUILLO, La defensa armada contra la revolución. Una historia de las «guardias cívicas» en la España del siglo XX, Madrid, CSIC, 1995.

61 Resumen normativo sobre tenencia y uso de armas (ca. 1925) y consulta realizada por el Gobierno Civil de Zaragoza (ca. 1925), en AHN, Gobernación, Serie A, leg. 3A, exp. n. ${ }^{\circ}$.

62 Véase «La nueva Ley sobre uso de armas», Revista Técnica de la Guardia Civil, n. 163, IX-1923, pp. 353-354.

${ }^{63}$ Carta del Director General de Seguridad, general Miguel Arlegui, al subsecretario del Ministerio de la Gobernación, Martínez Anido (19-XI-1924), sobre la aplicación de la legislación entonces vigente a la tenencia de sustancias explosivas (AHN, Gobernación, Serie A, leg. $3 A$, exp. n. ${ }^{\circ} 5$ ). 


\section{REFORZAMIENTO Y CRISIS DE UN SISTEMA MILITARIZADO DE CONTROL COLECTIVO: LA DICTADURA DE PRIMO DE RIVERA}

Aunque no cabe duda de que el desarrollo del Estado moderno ha producido herramientas cada vez más poderosas y profesionalizadas para el control de las actividades políticas de los grupos disidentes, el grado de actuación represiva varía sustancialmente en función del tipo de gobierno. Por definición, los regímenes autoritarios de carácter represivo, como fue la Dictadura de Primo de Rivera, desaniman toda manifestación política de carácter popular, suspendiendo el normal intercambio entre la acción colectiva más o menos organizada y la necesaria flexibilidad de las autoridades a la hora de negociar las exigencias de los grupos contestatarios.

El hecho, destacado certeramente por Enric Ucelay, de que el régimen de Primo no fuese especialmente sanguinario ni muy diferente de la situación política anterior en cuanto al empleo de medios de fuerza para la resolución de los problemas de orden público, no significa que no fuese, por su propia esencia, sustancialmente más represivo que los gobiernos que le precedieron ${ }^{64}$. Es cierto que, como sentenciaba Francisco Villanueva, la Dictadura no fusilaba, pero mataba sin efusión de sangre ${ }^{65}$, al manejar a su antojo todos los resortes que impedían cualquier manifestación de hostilidad. La Dictadura adoptó medidas represivas más o menos sistemáticas sobre las libertades individuales y públicas, que quedaron en entredicho tras la supresión de garantías y la declaración sine die del estado de guerra hasta su temporal levantamiento, se especula que por presiones castrenses, en mayo de 1925. Por último, el anteproyecto de la Ley de Orden Público de 1929 autorizaba al Gobierno a suspender la totalidad de los derechos consignados en el artículo III de la maltrecha Constitución. De ese modo, no fueron excepcionales la violación de correspondencia, los confinamientos arbitrarios, las multas desaforadas o las prolongadas incomunicaciones de presos gubernativos ${ }^{66}$.

La intromisión de la jurisdicción castrense en ámbitos hasta entonces reservados a las instancias civiles fue otra característica de la política dictatorial, aunque el Directorio no actuase en esta línea de forma sistemática, sino mediante la publicación de disposiciones forzadas por los acontecimientos del momento. Un Real Decreto de 18 de septiembre de 1923 sometió a los tribunales militares los delitos contra la seguridad y la unidad de la patria ${ }^{67}$, y otro de 17 de marzo de 1926

64 Enric UCELAY DA CAL, «La repressió de la Dictadura de Primo de Rivera», en I/es. Jornades de debat El poder de l'Estat: evolució, força o raó, Reus, Edicions del Centre de Lectura, 1993, pp. 155 y 159.

65 Francisco VILLANUEVA, La Dictadura Militar. II tomo de “Obstáculos tradicionales». Crónica documentada de la oposición y de la represión bajo el Directorio (1923-1926), Madrid, Javier Morata, editor, 1930 , pp. 111 y 115.

66 Véanse al respecto los testimonios de Luis JIMENEZ DE ASÚA, Notas de un confinado, Madrid, Ed. Mundo Latino (CIAP), 1930, pp. 13-31 y Rafael SALAZAR ALONSO, La justicia bajo la Dictadura, Madrid, Eds. Zeus, 1930, pp. 123-128.

67 Texto de este Real Decreto, en marqués de CASA RAMOS y conde de la MORALEDA, Dos años de Directorio Militar. Manifiestos, disposiciones oficiales, cartas, discursos, órdenes generales del Ejército, etc., etc., Madrid, Renacimiento, ¿1926?, pp. 39-40. 
reprimía otros actos de separatismo. Con posterioridad al regicidio frustrado de Garraf, un Real Decreto de 25 de diciembre de 1925 dispuso que la Jurisdicción de Guerra fuera la única competente para conocer de los delitos comprendidos en la Ley sobre Explosivos de 10 de julio de 1894 (que prescribía el juicio por Jurado), en los de traición y en los de lesa majestad, hasta entonces previstos y castigados por el Código Penal común ${ }^{68}$. Un Real Decreto de 16 de mayo de 1926 -es decir, poco después del complot de la «Sanjuanada»-, otorgaba al Gobierno facultades discrecionales para imponer las «sanciones que estén dentro de sus facultades y proponiéndome las que excedan de ella, incluso los destierros y deportaciones que crea necesario, sea cualquiera su número y la calidad de las personas que lo merezcan». El nuevo Código Penal de septiembre de 1928 amplió el ámbito del delito de rebelión a las huelgas y a los paros laborales, y con la aparición de entidades de «defensa cívica» como el Somatén Nacional (cuyos miembros tenían desde el 8 de septiembre de 1924 el rango de agentes de la autoridad incluso cuando se encontraban fuera de servicio), el delito de atentado fue ampliado a la agresión sobre toda persona constituida en autoridad, aunque no se hallase ejerciendo funciones de su cargo, como estipulaba el Código de $1870^{69}$.

La Dictadura fue también generosa a la hora de constituir instancias jurisdiccionales de carácter específico, competentes en determinados delitos de orden político. A la altura de abril de 1928 actuaba un Juzgado de Instrucción Especial Anticomunista con competencias en todo el territorio nacional, y tras la intentona de Sánchez Guerra, un Decreto de la Presidencia del Gobierno creó el 3 de febrero de 1929 otro Tribunal Especial de ámbito nacional, vinculado al Ministerio del Interior y a la DGS bajo la dependencia del Consejo de Ministros, para que actuase en los atestados y primeras diligencias en los «hechos delictivos que afecten a la seguridad exterior del Estado o se dirijan contra los Poderes constituidos o el orden público", y otros delitos que el Ministerio del Interior estimase oportuno someter a su jurisdicción ${ }^{70}$.

La ampliación, indefinida y a menudo caótica, de la jurisdicción castrense a todos los ámbitos administrativos, produjo también la subsiguiente oleada de destituciones en Ayuntamientos, Diputaciones, Mancomunidades, Tribunales, sociedades profesionales, etc., y los situó bajo la férula omnipotente de los gobernadores militares y los delegados gubernativos.Los resortes superiores del orden público fueron despolitizándose y cayendo en manos del personal más «técnico» de la etapa anterior $^{71}$. El aparato policial pasó al control de los dos máximos responsables del

68 El Decreto, en Joan CREXELL I PLAYÀ, El complot de Garraf, Barcelona, Publicacions de l'Abadia de Montserrat, 1988, pp. 210-212.

69 SALAZAR ALONSO, La justicia bajo la Dictadura, p. 285. El Real Decreto-Ley aprobando el proyecto de Código Penal, que empezó a regir como Ley el 1-I-1929, en Revista Técnica de la Guardia Civil, n. ${ }^{\circ}$ 225, XI-1928, pp. 523-624. El Código Penal de 1928 fue derogado por Decreto de 15-IV-1931 (Gaceta $\left.n .^{\circ} 106\right)$.

70 Véanse «Importantes disposiciones del Gobierno», Noticiero del Lunes, 4-II-1929, p. 1 y SALAZAR ALONSO, La justicia bajo la Dictadura, pp. 130-131.

71 Jordi CASASSAS YMBERT, «Noves actituds i velles qüestions: el cas de la dictadura», L'Avenç, n. ${ }^{\circ} 72$, junio 1984 , p. 43. 
orden público en Barcelona durante los más oscuros años del pistolerismo: Martínez Anido fue nombrado subsecretario de Gobernación, y Arlegui director general de Orden Público, cuyas prerrogativas quedaron notablemente ampliadas cuando el 20 de octubre de 1923 fue suprimida la Dirección General de Orden Público creada en 1908, y el 7 de noviembre fue puesto al frente de la restablecida Dirección General de Seguridad, con lo que asumió el mando directo de los Cuerpos de Vigilancia y Seguridad, aunque la Guardia Civil recuperó la autonomía perdida con el Real Decreto de 16 de junio de $1921^{72}$. Como colofón a esta reforma de los instrumentos coactivos del Estado, la Asamblea Nacional discutió en abril de 1929 un proyecto de Ley de Orden Público que pretendía sustituir la vetusta Ley de 23 de abril de 1870, en el sentido de conceder discrecionalidad al Ejecutivo en la declaración de los estados de prevención y alarma. El estado de guerra podría proclamarse previa decisión de las autoridades militar, civil y judicial, pero en la capital no podría declararse sin la autorización del Gobierno), que sin embargo podría imponer esta situación excepcional en cualquier provincia o pueblo ${ }^{73}$.

La dinámica interna de la propia burocracia policial influye no poco en el desarrollo de las diversas estrategias de control social que emprende un Estado. Antes que perseguir la paz pública mediante la represión, la disuasión o el castigo, los policías perciben la preservación del orden como un vehículo para el progreso profesional o la perpetuación y el incremento de sus intereses corporativos. Durante la Dictadura, la militarización efectiva de los medios de control social y la aplicación de instrumentos legislativos excepcionales no condujeron a una mejora objetiva de la situación corporativa de la Policía. Más bien todo lo contrario. Aunque la actuación represiva fue esporádica y selectiva en comparación con los amplios medios disponibles ${ }^{74}$, la actividad policial no logró la tan ansiada profesionalización científica y legalista ${ }^{75}$. El debilitamiento de los controles internos hizo que la labor del Cuerpo de Vigilancia (en especial la de la División de Investigación Social, creada de forma oficial por Real Orden de 22 de noviembre de 1926 y compuesta por una docena de Brigadas que cubrían toda España) se resintiera por las rivalidades domésticas, por las conveniencias particulares de la jerarquía, por el recurso sistemático a confidentes poco fiables, por el trato de favor otorgado a agentes sin escrúpulos, y por la persecución en forma de sanciones, relegación y vacío profesional sobre los inspectores más íntegros, que se negaron a colaborar en las maniobras provocativas o intoxicadoras conducidas desde la DGS, como el cha-

72 El Real Decreto de supresión de la Secretaría General de Orden Público (20-X-1923) y el de restablecimiento de la DGS en el Ministerio de la Gobernación (7-XI-1923, Gaceta de 9-XI-1923, pp. 587-589 y rectificado en Gaceta de 10-XI-1923, pp. 602-604), en CASA RAMOS y MORALEDA, Dos años de Directorio Militar, pp. 93 y 120-123, respectivamente.

73 El Proyecto de Ley de Orden Público (22-IV-1928), en Archivo del Congreso de los Diputados, Serie General, Actas de la Comisión de Leyes Constituyentes, leg. 667. Esta reforma no pudo ser aplicada por la oposición del rey, que de este modo precipitó la dimisión de Primo en enero de 1930.

74 Javier TUSELL GÓMEZ y Genoveva GARCÍA QUEIPO DE LLANO, «La Dictadura de Primo de Rivera como régimen político. Un intento de interpretación», Cuadernos Económicos de I.C.E., n. ${ }^{10}$, 1979, p. 52.

75 UCELAY, «La repressió de la Dictadura de Primo de Rivera», pp. 175-176. 
pucero montaje policial de Vera de Bidasoa en el otoño de 1925, perpetrado un año después de la fallida irrupción fronteriza protagonizada por los anarquistas y otros grupos de oposición a la Dictadura ${ }^{76}$.

El último año de vida del régimen dictatorial contempló una inquietante deriva «totalitarista» de la política de orden público, que implicó a sus entidades «cívicas» de apoyo. El artículo $3 .^{a}$ del Real Decreto de 3 de febrero de 1929 indicaba que «la agrupación ciudadana Unión Patriótica, conservando su actual carácter y estructura, tendrá carácter oficioso y su organización se extenderá a crear centros de investigación e información ciudadana, colaboradora de las autoridades en cuanto pueda afectar al sostenimiento del orden público». En su artículo $4 .^{\circ}$ advertía que «el Somatén nacional acentuará la prestación de sus servicios dentro de la peculiaridad de su misión ${ }^{77}$. Como complemento de la anterior disposición, en el artículo 5. ${ }^{\circ}$ de la Real Orden Circular n. 70 de 8 de febrero se ordenaba que las oficinas de Somatenes y de la Unión Patriótica organizaran, bajo la custodia personal del jefe local, un registro de personas «propicias a la difamación, el alboroto político y la desmoralización del ánimo público", que serían susceptibles de ser puestos a disposición de las autoridades en cualquier momento ${ }^{78}$. Mediante otra Real Orden Circular (la n. ${ }^{\circ} 187$, de 16 de abril), Primo de Rivera facultaba el registro de los domicilios de los sospechosos por parte de estas entidades, calificadas de «auxiliares militares», lo cual acarreó nuevos e inevitables roces con la Policía Gubernativa ${ }^{79}$.

Primo de Rivera había tratado de solucionar las dos principales contradicciones del régimen restauracionista en materia de orden público (una intervención castrense más acusada, que coincidió con la desconfianza de los medios sociales conservadores en los resortes tradicionales del orden público), integrándolas en condiciones de normalidad en el aparato del Estado. Por un lado, el dictador superó la intromisión militarista en las cuestiones de seguridad interior concediendo la gestión exclusiva del aparato policial a los militares más implicados a ese respecto en los anteriores conflictos con el poder civil (Anido y Arlegui). De igual modo, la «privatización» parcial de las cuestiones de seguridad impulsada en los años anteriores por los grupos «de orden» trató de ser canalizada mediante la oficialización del Somatén, y su generalización a toda España como institución semipolítica de apoyo activo al régimen y como elemento parapolicial de auxilio a la autoridad en caso de disturbios. Pero el fracaso en lograr tanto el consenso como la movilización permanente de estos sectores conservadores condujo al declive del régimen. El agotamiento de la experiencia dictatorial y las divisiones y hostilidades de carácter político e institucional que ésta provocó en el interior del sistema de poder monárquico mermaron la legitimidad de éste, y lo dejó inerme ante sus enemigos.

76 Sobre esta cuestión véase GONZÁLEZ CALLEJA, El máuser y el sufragio, pp. 288-290.

77 «Importantes disposiciones del Gobierno», Noticiero del Lunes, 4-II-1929, p. 1 y SALAZAR ALONSO, La justicia bajo la Dictadura, pp. 130-131.

78 El texto de la Real Orden, en EI Sol, 9-II-1929, p. 1 y SALAZAR ALONSO, La justicia bajo la Dictadura, pp. 261-263.

79 El Somatén, n. ${ }^{\circ}$ 4, IV-1929, pp. 3-4 y Paz y Buena Voluntad, n. ${ }^{\circ} 61$, V-1929, p. 3. 


\section{EPÍLOGO: EL DERRUMBE DE LA POLÍTICA DE ORDEN PÚBLICO Y LA CAÍDA DE LA MONARQUÍA}

La caída del régimen primorriverista no supuso una mejora en la eficacia de los mecanismos estatales de regulación del conflicto. La agudización del ciclo de protesta, que ya extendía el alcance de sus críticas al mismo régimen monárquico fue afrontada con los tradicionales recursos represivos de un sistema de orden público que conservó su impronta castrense hasta el último instante. Mola, director general de Seguridad desde el 11 de febrero de 1930, trató de regenerar una función policial lastrada desde hacía años por las rivalidades intestinas, la excesiva militarización, la carencia de personal y medios y la dudosa conducta social y política de parte de los funcionarios ${ }^{80}$. Hasta fines de año obtuvo un aumento de la plantilla en cerca de un millar de guardias, y el 25 de noviembre consiguió aprobar el Reglamento Orgánico de la Policía Gubernativa, en realidad una recopilación de la normativa preexistente, que tras su supresión por la República estuvo vigente en el régimen franquista hasta 1975. El Real Decreto dio primacía al Cuerpo de Vigilancia sobre el de Seguridad, y centralizó las actuaciones de ambos en la DGS, aunque en provincias la Policía se mantuvo bajo la dependencia directa de los gobernadores civiles ${ }^{81}$. Se trató de reorganizar el servicio de información y la red de confidentes, y se mantuvo la colaboración con la Guardia Civil en los términos de ambigüedad establecidos por el Real Decreto de 7 de noviembre de 1923. Con esta última tentativa de reforma de la Policía abordada antes de la proclamación de la República, Mola trató de culminar un proceso de centralización ya iniciado en la década de los diez, y que había quedado pospuesto durante la Dictadura por culpa de las rivalidades entre los mandos responsables de los distintos cuerpos, en especial la Policía y la Guardia Civil.

A pesar de diseñarse planes detallados de movilización de las fuerzas de orden y de almacenamiento de armas de fuego en caso de intentona revolucionaria ${ }^{82}$, a la hora de la verdad los servicios policiales se desmoronaron en la primavera de 1931 con la misma rapidez con que avanzó la ola de opinión contraria a la Monarquía. Numerosos funcionarios dieron muestras de conducta dudosa o de malévola inhibición, abriendo camino a un rosario de intrigas que permitió a muchos de ellos conservar sus puestos durante la República, y conspirar contra ella en épocas posteriores. La aparición de casos de «vigilantismo» como el Partido Nacionalista Español fue una muestra evidente de que el Gobierno era incapaz de hacer res-

80 Sobre la situación interna de la Policía en esa época, véase Emilio MOLA VIDAL, «Lo que yo supe... Memorias de mi paso por la Dirección general de Seguridad», en Obras Completas, Madrid, Librería Santarén, 1940, pp. 240-245.

81 MINISTERIO DE LA GOBERNACIÓN, Reglamento orgánico de la Policía gubernativa, Madrid, Ed. Reus, 1931.

82 Véanse Orden de concentración de fuerzas de la Guardia Civil dirigida por Mola a los gobernadores civiles (8-IX-1930), y Orden del ministro de la Gobernación de 3-IX-1930 sobre protección de servicios esenciales, en AGM, 2. ${ }^{a}$ Sección, 10. ${ }^{a}$ División, leg. n. ${ }^{\circ} 149$. La Circular n. 82 del Ministerio de la Gobernación sobre control de armas (1-X-1930), en AHN, Gobernación, Serie A, leg. 4, exp. n. ${ }^{\circ} 12$. 
petar las normas sociopolíticas con los recursos institucionales a su alcance. A esta espectacular merma de eficacia coercitiva se sobrepuso una aguda crisis de legitimidad del régimen alfonsino, que condujo a los organismos militarizados de orden público (el Ejército dirigido por Berenguer y la Guardia Civil liderada por Sanjurjo) a desertar de sus tradicionales funciones de salvaguardia del régimen monárquico en las decisivas jornadas del 13 y 14 de abril. La inhibición en el pleito político, con que se quiso soslayar las divisiones internas de la corporación castrense y el hastío por los años de responsabilidad directa en la gestión del orden público, permitió proclamar de la República con una facilidad que llenó de asombro a sus mismos promotores.

La Restauración no cambió sustancialmente una concepción del orden público basada en un modelo político militarizado antes que un modelo civil profesionalizado. El paradigma centralista de la seguridad interior se caracterizaba por la preocupación respecto del mantenimiento del orden en la capital del Estado, por la militarización efectiva de los resortes institucionales y jurídicos del orden público; por el peso estratégico otorgado a la ocupación militar del territorio, y por la orientación predominantemente represiva sobre la población, antes que por la constitución de cuerpos adiestrados y especializados en misiones preventivas de investigación o vigilancia ${ }^{83}$. Y es que en España, donde la propia Policía se ha contemplado a sí misma como la larga mano del Poder Ejecutivo antes que como una institución al servicio del ciudadano, se ha tendido a la preservación de la ley y el orden antes que a la prevención, el control o la investigación de los delitos.

${ }^{83}$ LÓPEZ GARRIDO, El aparato policial en España, p. 64. 


\begin{tabular}{|c|c|c|c|c|c|c|c|}
\hline \multirow{3}{*}{ 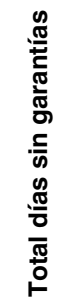 } & $\begin{array}{r}\frac{0}{\pi} \\
\circ \frac{0}{0} \\
\frac{\pi}{c} \\
\sum\end{array}$ & $\begin{array}{l}0 \\
0 \\
0 \\
0 \\
0\end{array} \mid$ & 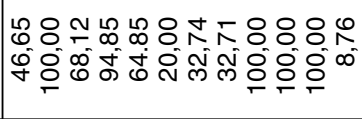 & 芯 & 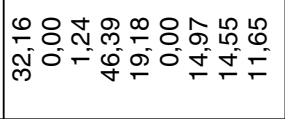 & in & $\begin{array}{l}898 \\
890 \\
0 \\
0\end{array}$ \\
\hline & $\circ^{\circ}$ & \begin{tabular}{|l|}
$\mathscr{Q}$ \\
$\mathscr{\infty}$ \\
$\infty$ \\
+ \\
\end{tabular} & 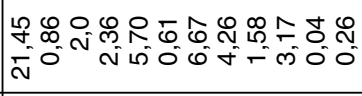 & 莫 & 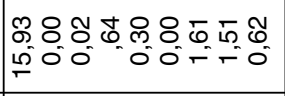 & ז & 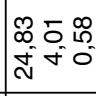 \\
\hline & : & ஜ্ֶ, & 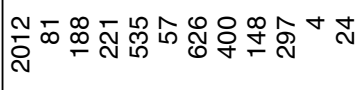 & 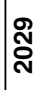 & 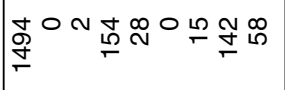 & 品 & श్ల్ \\
\hline \multirow{4}{*}{ 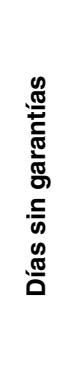 } & $\circ^{\circ}$ & $\left|\begin{array}{c}\infty \\
\infty \\
\infty \\
\infty \\
\infty \\
0\end{array}\right|$ & 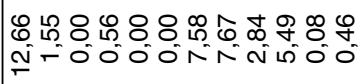 & 6 & $\begin{array}{l}\infty \\
4 \\
0 \\
0\end{array}$ & 苂 & 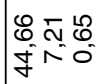 \\
\hline & 丞 & ลิ่ & প্ট & $\underbrace{\infty}$ & 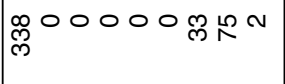 & 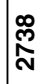 & 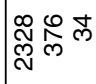 \\
\hline & $0^{\circ}$ & $\left|\begin{array}{l}0 \\
\frac{1}{6} \\
\overline{6}\end{array}\right|$ & 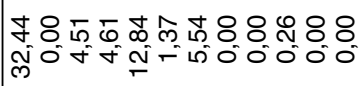 & 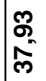 & 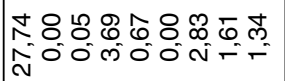 & 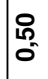 & 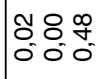 \\
\hline & ब్ర & 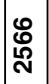 & 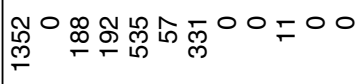 & 冓 & 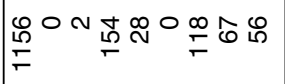 & $\bar{n}$ & -0 N \\
\hline \multirow{4}{*}{ 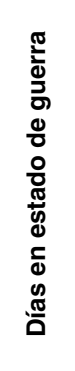 } & $\circ^{\circ}$ & $\begin{array}{l}\mathscr{Z} \\
\mathcal{F} \\
\hat{f}\end{array}$ & 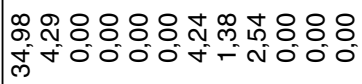 & 茎 & 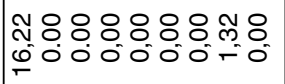 & 总 & 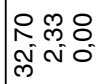 \\
\hline & 要 & 吔 & 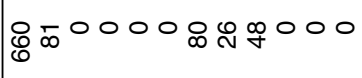 & $\overline{ল ্ ল ~}$ & 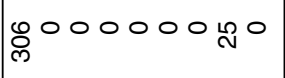 & $\bar{\varnothing}$ & $\frac{\hat{\sigma}}{6} \forall$ \\
\hline & $0^{\circ}$ & $\begin{array}{l}0 \\
\tilde{m} \\
\dot{8}\end{array}$ & $\begin{array}{l}m \\
\infty \\
\infty\end{array}$ & m & 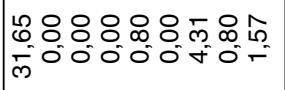 & 皁 & 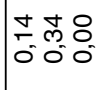 \\
\hline & 厄.্త & $\frac{\infty}{\grave{N}}$ & 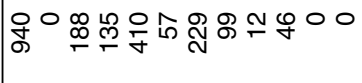 & $\underset{\text { N }}{\bar{m}}$ & 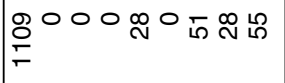 & 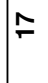 & 0 \\
\hline \multirow{2}{*}{ 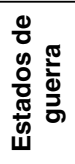 } & 丞 & $m$ & $0-0$ & $\theta$ & No00000r- & a & --0 \\
\hline & $\begin{array}{l}\overline{\text { बु }} \\
\end{array}$ & 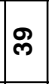 & 00 & ₹ & $\infty \sim 0$ & - & -00 \\
\hline \multirow{2}{*}{ 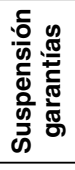 } & 嵒 & $\theta$ & -0000 & n & m00000-N- & - & -00 \\
\hline & ס్ర & $\infty$ & $-0 M 0 N 00000$ & & $\forall 0-000 \mathrm{MNN}$ & - & $-0-$ \\
\hline \multirow{2}{*}{ 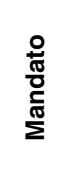 } & $\circ \circ$ & $\begin{array}{l} \\
\stackrel{8}{\mathcal{F}} \\
\end{array}$ & 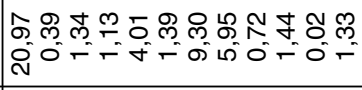 & প্ল্ণ & 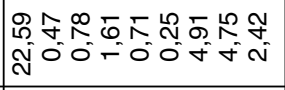 & 告 & 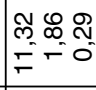 \\
\hline & 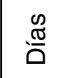 & $\begin{array}{c}\pi \\
\infty \\
\infty\end{array}$ & 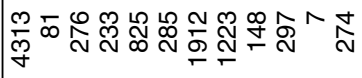 & న⿳亠口冋亍 & 唄 & ลָ & ఖ్ల్ల \\
\hline \multicolumn{2}{|c|}{ 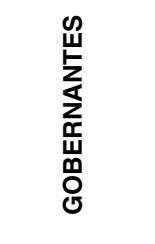 } & 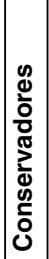 & 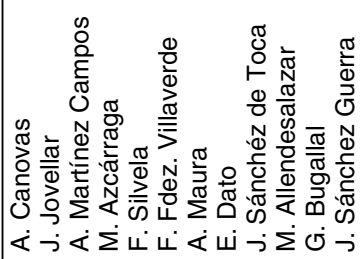 & $\frac{\sqrt{\frac{\pi}{\pi}}}{\frac{\pi}{0}}$ & 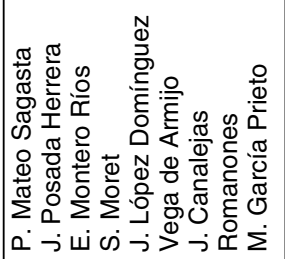 & 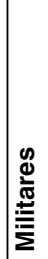 & 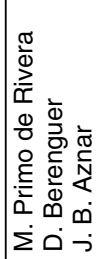 \\
\hline
\end{tabular}


CuAdro 2. La suspensión de las garantías constitucionales en Cataluña durante la restauracion (1875-1931)

\begin{tabular}{|c|c|c|c|c|c|}
\hline \multirow{2}{*}{ AÑOS } & \multicolumn{2}{|c|}{ Días en estado de guerra } & \multicolumn{2}{|c|}{ Días sin garantías } & \multirow{2}{*}{ TOTAL } \\
\hline & Barcelona & Cataluña & Barcelona & Cataluña & \\
\hline $\begin{array}{l}1875 \\
1876 \\
1877 \\
1878 \\
1879 \\
1880 \\
1881 \\
1882 \\
1883 \\
1884 \\
1885 \\
1886 \\
1887 \\
1883 \\
1889 \\
1890 \\
1891 \\
1892 \\
1893 \\
1894 \\
1893 \\
139 \\
13 \\
\mid\end{array}$ & $\begin{array}{r}0 \\
0 \\
0 \\
0 \\
0 \\
6 \\
0 \\
13 \\
0 \\
0 \\
0 \\
0 \\
0 \\
0 \\
0 \\
51 \\
0 \\
0 \\
54 \\
365 \\
0 \\
0 \\
0 \\
0 \\
0 \\
0 \\
8 \\
234 \\
0 \\
0 \\
0 \\
0 \\
0 \\
154 \\
23 \\
0 \\
0 \\
0 \\
0 \\
0 \\
0 \\
0 \\
11 \\
72 \\
18 \\
1 \\
0 \\
0 \\
0 \\
0 \\
0 \\
0 \\
0\end{array}$ & $\begin{array}{r}36 \\
366 \\
10 \\
0 \\
0 \\
0 \\
0 \\
3 \\
0 \\
0 \\
29 \\
0 \\
0 \\
0 \\
0 \\
0 \\
0 \\
46 \\
0 \\
0 \\
0 \\
0 \\
0 \\
238 \\
39 \\
234 \\
68 \\
0 \\
0 \\
0 \\
0 \\
0 \\
0 \\
0 \\
0 \\
0 \\
0 \\
0 \\
0 \\
0 \\
0 \\
0 \\
0 \\
0 \\
0 \\
0 \\
0 \\
0 \\
0 \\
0 \\
0 \\
0 \\
0 \\
0 \\
0 \\
0 \\
0 \\
0 \\
0 \\
0 \\
0 \\
0 \\
0 \\
0 \\
0\end{array}$ & $\begin{array}{r}0 \\
0 \\
0 \\
0 \\
0 \\
0 \\
0 \\
10 \\
0 \\
0 \\
0 \\
0 \\
0 \\
0 \\
0 \\
51 \\
0 \\
0 \\
54 \\
365 \\
0 \\
147 \\
351 \\
0 \\
70 \\
132 \\
1 \\
316 \\
29 \\
0 \\
33 \\
105 \\
0 \\
154 \\
42 \\
0 \\
0 \\
0 \\
0 \\
0 \\
0 \\
0 \\
0 \\
73 \\
03 \\
0 \\
0 \\
0 \\
0 \\
0 \\
0 \\
0 \\
0 \\
0 \\
0 \\
0 \\
0 \\
0 \\
0 \\
0 \\
0 \\
0\end{array}$ & $\begin{array}{r}365 \\
366 \\
10 \\
0 \\
0 \\
0 \\
0 \\
3 \\
24 \\
0 \\
29 \\
0 \\
0 \\
0 \\
0 \\
0 \\
0 \\
46 \\
0 \\
0 \\
0 \\
0 \\
0 \\
238 \\
39 \\
234 \\
76 \\
0 \\
0 \\
0 \\
0 \\
0 \\
0 \\
109 \\
366 \\
365 \\
365 \\
365 \\
366 \\
365 \\
365 \\
0 \\
63 \\
0 \\
33 \\
0 \\
146 \\
331 \\
0 \\
0 \\
0 \\
30 \\
0 \\
0 \\
0\end{array}$ & $\begin{array}{r}365 \\
366 \\
10 \\
0 \\
0 \\
0 \\
0 \\
13 \\
24 \\
0 \\
29 \\
0 \\
0 \\
0 \\
0 \\
51 \\
0 \\
46 \\
54 \\
365 \\
0 \\
147 \\
351 \\
238 \\
109 \\
366 \\
77 \\
316 \\
29 \\
0 \\
310 \\
366 \\
365 \\
365 \\
365 \\
366 \\
365 \\
0 \\
154 \\
105 \\
0 \\
30\end{array}$ \\
\hline TOTAL & 1010 & 1948 & 2127 & 5411 & 7538 \\
\hline
\end{tabular}




\begin{tabular}{|c|c|c|c|c|c|c|c|c|c|c|c|c|c|c|c|c|c|c|c|c|c|c|c|c|c|c|c|c|}
\hline 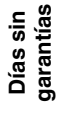 & $\stackrel{m}{\sim}$ & 0 & ల) & 0 & 0 & 0 & 0 & $\bar{m}$ & $\stackrel{2}{\sim}$ & 0 & 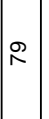 & ले & 0 & $\stackrel{\stackrel{2}{\circ}}{\leftarrow}$ & 迆 & $\sim$ & 웅 & $\stackrel{\widehat{N}}{\sim}$ & & & 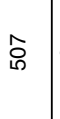 & 0 & 0 & 0 & & 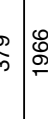 & $\underset{\sim}{\infty}$ & $\stackrel{Q}{\circ}$ \\
\hline : & $\mp$ & $\stackrel{\infty}{\stackrel{\infty}{N}}$ & 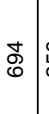 & 怘 & $\stackrel{\widetilde{m}}{\sim}$ & $\stackrel{\substack{N \\
N}}{N}$ & 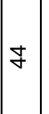 & 总 & 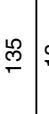 & $\stackrel{\infty}{\leftarrow}$ & ৪ & $\stackrel{\infty}{\stackrel{\infty}{\wedge}}$ & 呫 & $\stackrel{m}{\frac{m}{\sigma}}$ & 足 & $\sim \stackrel{\infty}{\sim}$ & $\stackrel{\infty}{\leftarrow}$ & $\stackrel{\widehat{N}}{\sim}$ & 悉 & $\begin{array}{l}\text { No } \\
\text { L }\end{array}$ & $\stackrel{n}{i}$ & న్ & $\stackrel{?}{?}$ & స & T) & \begin{tabular}{c|c}
$\qquad: 8$ \\
\hdashline
\end{tabular} & $\mid \begin{array}{l}\infty \\
\sim \\
\sim\end{array}$ & $\tau$ \\
\hline 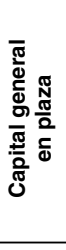 & 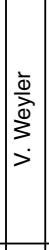 & $\begin{array}{l}\frac{\grave{\omega}}{\vec{d}} \\
\stackrel{\vec{d}}{>} \\
\bar{c}\end{array}$ & $\begin{array}{l}\frac{\omega}{\omega} \\
\vec{a} \\
3 \\
> \\
>\end{array}$ & 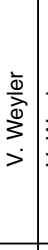 & $\begin{array}{l}\frac{\bar{\omega}}{3} \\
\frac{\omega}{3} \\
>\end{array}$ & 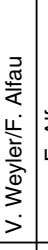 & 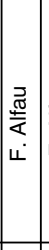 & 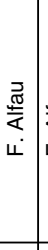 & 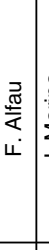 & 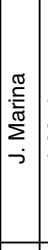 & 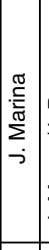 & 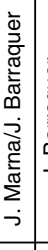 & 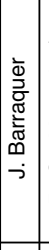 & 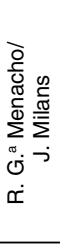 & 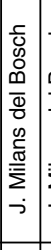 & 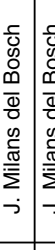 & 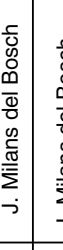 & 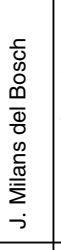 & 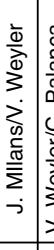 & 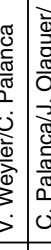 & 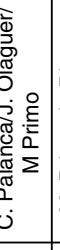 & 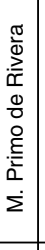 & 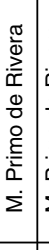 & 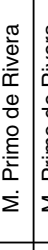 & & 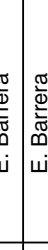 & 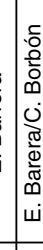 & 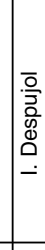 \\
\hline 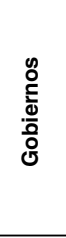 & 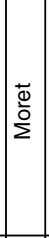 & 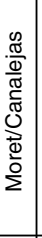 & 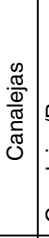 & 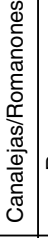 & 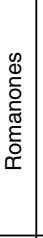 & $\begin{array}{l}0 \\
\stackrel{\pi}{\pi} \\
\Delta\end{array}$ & 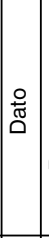 & 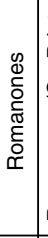 & 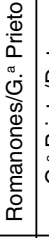 & 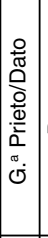 & \begin{tabular}{|l|} 
\\
$\frac{8}{\pi}$ \\
\end{tabular} & 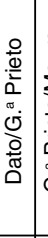 & 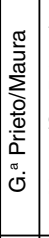 & 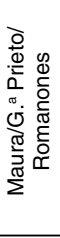 & 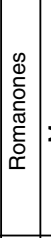 & 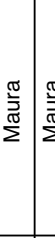 & 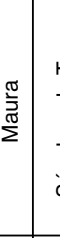 & 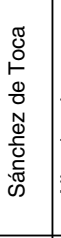 & 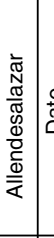 & & 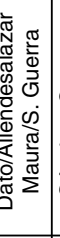 & 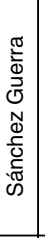 & 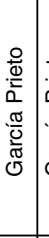 & 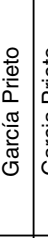 & 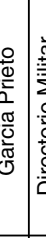 & 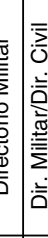 & 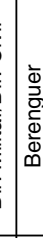 & 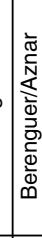 \\
\hline 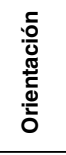 & 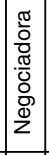 & $\begin{array}{l}\frac{\pi}{0} \\
\frac{0}{0} \\
\frac{\pi}{0} \\
\frac{0}{0} \\
\frac{\Phi}{2} \\
\end{array}$ & $\begin{array}{l}\frac{\pi}{0} \\
\frac{0}{0} \\
\frac{\pi}{0} \\
0 \\
\frac{0}{2} \\
\frac{0}{2}\end{array}$ & 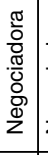 & $\begin{array}{l}\frac{\pi}{0} \\
\frac{0}{0} \\
\frac{\pi}{0} \\
\frac{0}{0} \\
\frac{\Phi}{2} \\
\end{array}$ & $\begin{array}{l}\frac{\pi}{0} \\
\frac{0}{0} \\
\frac{\pi}{0} \\
0 \\
0 \\
\frac{\mathbb{d}}{2} \\
\end{array}$ & 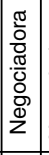 & 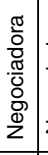 & $\begin{array}{l}\frac{\pi}{0} \\
\frac{0}{0} \\
\frac{\pi}{0} \\
0 \\
\frac{\Phi}{2} \\
\end{array}$ & 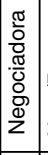 & 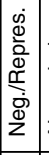 & 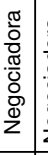 & 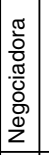 & 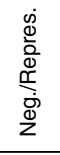 & 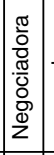 & ¿. & 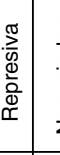 & $\begin{array}{l}\frac{\pi}{0} \\
\frac{0}{0} \\
\frac{\pi}{0} \\
\frac{0}{0} \\
\frac{\Phi}{2}\end{array}$ & 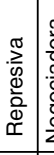 & 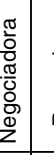 & $\begin{array}{l}\frac{\pi}{0} \\
\frac{0}{0} \\
\frac{0}{0}\end{array}$ & 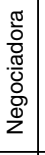 & $\begin{array}{l}\frac{\pi}{0} \\
\frac{0}{0} \\
\frac{\pi}{0} \\
0 \\
\frac{\Phi}{2} \\
\end{array}$ & & & & 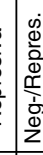 & 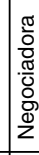 \\
\hline 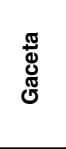 & 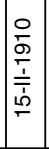 & 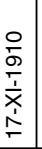 & 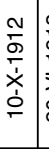 & 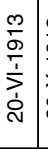 & $\begin{array}{l}m \\
\frac{m}{\sigma} \\
\frac{\dot{x}}{\dot{x}} \\
\dot{c}\end{array}$ & 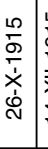 & \begin{tabular}{|l|}
0 \\
$\frac{1}{0}$ \\
$\frac{1}{1}$ \\
$\bar{x}$ \\
$\dot{j}$ \\
\\
\end{tabular} & 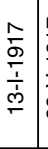 & 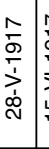 & 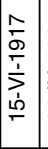 & 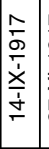 & 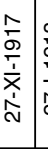 & $\begin{array}{l}\infty \\
\frac{\infty}{\sigma} \\
\frac{T}{1} \\
\frac{1}{N}\end{array}$ & $\begin{array}{l}\stackrel{\sigma}{\sigma} \\
\frac{\sigma}{1} \\
\overline{\bar{J}} \\
\dot{J}\end{array}$ & 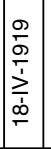 & 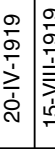 & 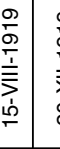 & $\frac{\frac{0}{\sigma}}{\frac{1}{\bar{x}}}$ & ه্ं & & 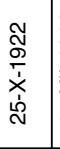 & 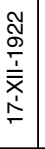 & 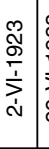 & 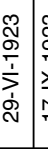 & & ن. & : & 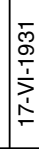 \\
\hline $\mathscr{\Xi}^{\circ}$ & 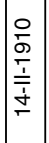 & 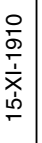 & $\begin{array}{l}N \\
\stackrel{N}{\sigma} \\
\bar{\sigma} \\
\dot{x} \\
\sigma\end{array}$ & $\begin{array}{l}\frac{m}{\sigma} \\
\frac{\sigma}{T} \\
\frac{1}{\sigma} \\
\frac{1}{\sigma}\end{array}$ & $\begin{array}{l}m \\
\frac{m}{\sigma} \\
\overline{\dot{x}} \\
\dot{\alpha} \\
\stackrel{N}{N}\end{array}$ & $\begin{array}{l}\stackrel{\circ}{\sigma} \\
\frac{\sigma}{\dot{\sigma}} \\
\stackrel{x}{\dot{\omega}} \\
\stackrel{\omega}{N}\end{array}$ & 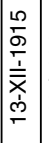 & 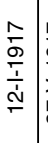 & 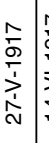 & 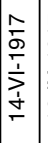 & 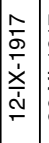 & 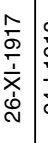 & 立 & 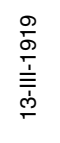 & 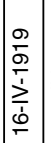 & 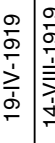 & 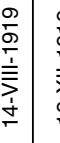 & 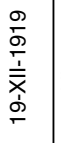 & 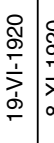 & శ్ & 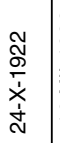 & $\mid$ & 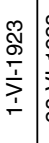 & 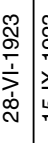 & 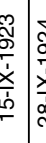 & 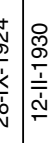 & 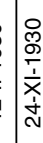 & ুু \\
\hline 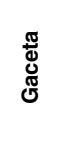 & 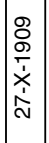 & 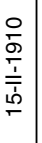 & $\begin{array}{l}\stackrel{0}{0} \\
\frac{\sigma}{1} \\
\frac{1}{x} \\
\stackrel{1}{\llcorner}\end{array}$ & 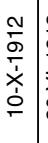 & 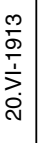 & 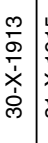 & \begin{tabular}{|l|}
$\frac{1}{2}$ \\
$\frac{0}{9}$ \\
$\frac{1}{x}$ \\
$\frac{1}{9}$ \\
\end{tabular} & 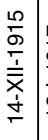 & $\begin{array}{l}\hat{\sigma} \\
\frac{\sigma}{\bar{\sigma}} \\
\frac{1}{\dot{S}} \\
\frac{1}{\sigma}\end{array}$ & 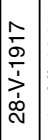 & 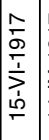 & 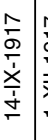 & 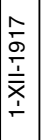 & $\begin{array}{l}\frac{\infty}{9} \\
\frac{7}{1} \\
\stackrel{+}{N}\end{array}$ & 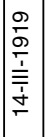 & 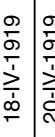 & 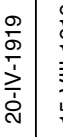 & 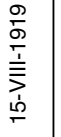 & 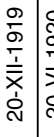 & & స్ & 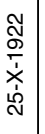 & 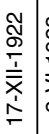 & ָָ & 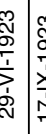 & 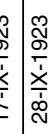 & 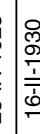 & 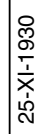 \\
\hline 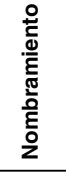 & 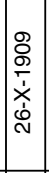 & 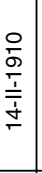 & 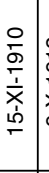 & 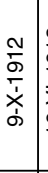 & $\begin{array}{l}\frac{m}{5} \\
\frac{5}{7} \\
\frac{1}{7} \\
0 \\
\frac{1}{\sigma}\end{array}$ & 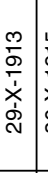 & 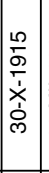 & 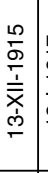 & 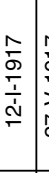 & 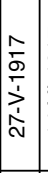 & $\mid \begin{array}{c}\frac{1}{2} \\
\frac{9}{2} \\
\frac{1}{2} \\
\frac{1}{5}\end{array}$ & 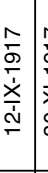 & \begin{tabular}{|l}
$\hat{N}$ \\
$\frac{\sigma}{T}$ \\
$\frac{1}{x}$ \\
$\dot{0}$ \\
$\bar{\rho}$
\end{tabular} & $\begin{array}{l}\frac{\infty}{\sigma} \\
\frac{\Gamma}{+} \\
\frac{1}{N}\end{array}$ & 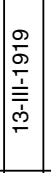 & 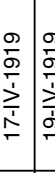 & $\frac{0}{\frac{0}{\sigma}}$ & 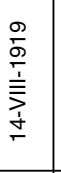 & 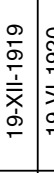 & & 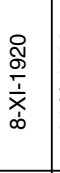 & 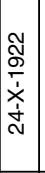 & 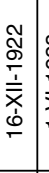 & & ్ָ & 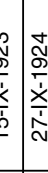 & 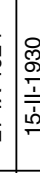 & ḋ \\
\hline 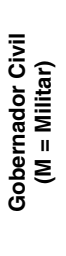 & 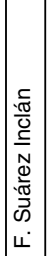 & 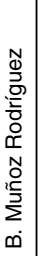 & 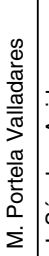 & 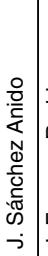 & 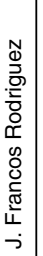 & 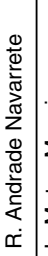 & 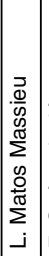 & 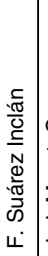 & 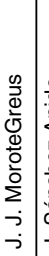 & 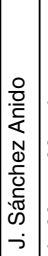 & 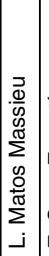 & 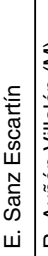 & 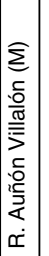 & 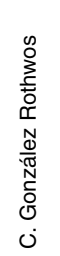 & 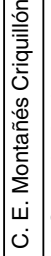 & 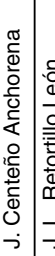 & 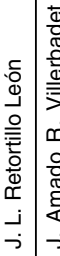 & 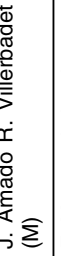 & 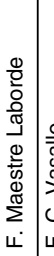 & & 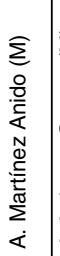 & 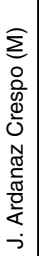 & 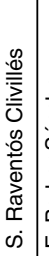 & & d & 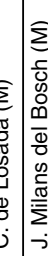 & 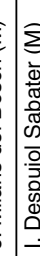 & $\begin{array}{l}\overline{\bar{J}} \\
\overline{\widetilde{J}} \\
\mathcal{J} \\
\mathbb{N} \\
\bar{D} \\
\bar{\sigma}\end{array}$ \\
\hline
\end{tabular}

